\title{
Verification of model simulated mass balance, flow fields and tabular calving events of the Antarctic ice sheet against remotely sensed observations
}

\author{
Diandong Ren $\cdot$ Lance M. Leslie $\cdot$ Mervyn J. Lynch
}

Received: 19 February 2012/Accepted: 16 July 2012/Published online: 1 August 2012

(C) The Author(s) 2012. This article is published with open access at Springerlink.com

\begin{abstract}
The Antarctic ice sheet (AIS) has the greatest potential for global sea level rise. This study simulates AIS ice creeping, sliding, tabular calving, and estimates the total mass balances, using a recently developed, advanced ice dynamics model, known as SEGMENT-Ice. SEGMENTIce is written in a spherical Earth coordinate system. Because the AIS contains the South Pole, a projection transfer is performed to displace the pole outside of the simulation domain. The AIS also has complex ice-watergranular material-bedrock configurations, requiring sophisticated lateral and basal boundary conditions. Because of the prevalence of ice shelves, a 'girder yield' type calving scheme is activated. The simulations of present surface ice flow velocities compare favorably with InSAR measurements, for various ice-water-bedrock configurations. The estimated ice mass loss rate during 2003-2009 agrees with GRACE measurements and provides more spatial details not represented by the latter. The model estimated calving frequencies of the peripheral ice shelves from 1996 (roughly when the 5-km digital elevation and thickness data for the shelves were collected) to 2009 compare well with archived scatterometer images. SEGMENT-Ice's unique, non-local systematic calving scheme is found to be relevant for tabular calving. However, the
\end{abstract}

\footnotetext{
D. Ren $(\bowtie)$

ASDI, Curtin University of Technology, Bentley, WA, Australia e-mail: rendianyun@gmail.com

D. Ren · M. J. Lynch

Department of Physics, Curtin University of Technology,

Bentley, WA, Australia

L. M. Leslie

CIMMS, College of Atmospheric and Geographic Sciences,

University of Oklahoma, Norman, OK, USA
}

exact timing of calving and of iceberg sizes cannot be simulated accurately at present. A projection of the future mass change of the AIS is made, with SEGMENT-Ice forced by atmospheric conditions from three different coupled general circulation models. The entire AIS is estimated to be losing mass steadily at a rate of $\sim 120 \mathrm{~km}^{3} / \mathrm{a}$ at present and this rate possibly may double by year 2100 .

Keywords Climate change - Ice sheet dynamics . Sea level rise $\cdot$ Ice shelf calving

\section{Introduction}

At present the Earth's climate is in an interglacial period. Predictions based on the eccentricity in the Earth's orbit suggest that interglacial conditions possibly could continue for another $10 \mathrm{kyr}$ (Berger and Loutre 2002). The relative abundance of glaciers, when compared with two of the last three interglacial periods, suggests that there still is room for sea level rise (SLR) from melting of the current cryosphere. Moreover, it is possible that anthropogenic greenhouse effects may drive further widespread warming in the upcoming decades (IPCC AR4 2007).

As the largest potential contributor to SLR, quantifying the Antarctic ice sheet (AIS, Fig. 1) total mass balance is important in understanding the global hydrological cycle and the fragile polar ecosystem consequences (Massom et al. 2009). The AIS, especially West Antarctica, has been actively studied (see reviews by Vaughan 2006; Rignot et al. 2008; van den Broeke et al. 2006). Considerable uncertainty remains in the current and future contributions to SLR from Antarctica. Before satellite altimetry was available, the net mass balance usually was estimated using the credit/debit method (Vaughan 2006). This approach is natural because 
the net mass balance simply is the difference between input and output. However, the credit/debit approach relies on the difference between snow accumulation and ice flux leaving the domain, both of which are large numbers that contain substantial uncertainty. Consequently, for some time, it was uncertain whether the Antarctic ice mass is growing, shrinking, or stable (Velicogna and Wahr 2006; Bentley and Giovinetto 1990; Bentley 1993). For example, the glaciological evidence examined by Bentley and Giovinetto (1990, 1991) suggested slow growth, while oceanographic evidence (Southern ocean temperature, salinity, and oxygen isotope ratios) indicated a net ice mass loss (Jacobs et al. 1992). Only since the late 1990s have convincing assessments been made, using satellite altimetry (Wingham et al. 1998) and Interferometic Synthetic Aperture Radar (InSAR, Rignot et al. 2005). Rignot et al. (2005) suggest ice loss rates of $\sim 6.8 \pm 0.3 \mathrm{~km}^{3} / \mathrm{a}$ in Wordie Bay, western Antarctic Peninsula (AP). Unfortunately, the steep coastal topography hinders altimetry. The Gravity Recovery And Climate Experiment (GRACE) data measure the sum total of ice mass change and post glacial rebound (PGR) for an area, which show a positive rate over the entire Antarctic continent (Velicogna and Wahr 2006). As it cannot differentiate between phases of water, changes for floating ice (ice shelves) cannot be recorded by the GRACE satellite pair.

Climate warming may increase snowfall in Antarctica's interior (Davis et al. 2005; Shepherd and Wingham 2007; Huybrechts et al. 2004), but also may increase ice flow near the upper surface, especially the coast where warmer air and ocean may erode buttressing ice shelves and mountain glaciers at lower latitudes (Thomas et al. 2004; Scambos et al. 2005; Rignot et al. 2004; De Angelis and Skvarca 2003). There are few in situ measurements, but airborne and satellite remote sensing measurements are useful in regional ice balance studies, despite limited temporal coverage (e.g., Rignot and Thomas 2002; Thomas et al. 2004; Zwally et al. 2005).

While observational studies cataloguing ongoing glacial changes are important for understanding the mechanisms, realistic, supportable predictions for the future state of the AIS are imperative. This study focuses on verification of a recently developed ice model, SEGMENT-Ice (Ren et al. 2011a, b; Ren and Leslie 2011), specifically its application to the AIS. The modeled total mass loss from the AIS is compared with GRACE measurements, surface ice velocities are compared with InSAR measurements and tabular calving of the peripheral ice shelves is compared with recent surveys from scatterometer images.

In the following, the SEGMENT-Ice ice dynamic/thermodynamic system is described in Sect. 2, focusing primarily on aspects relevant for simulating the AIS. Emphasis is on a non-local ice calving scheme, which is activated for AIS simulations because of the prevalence of ice shelves on the periphery. SEGMENT-Ice is written in a

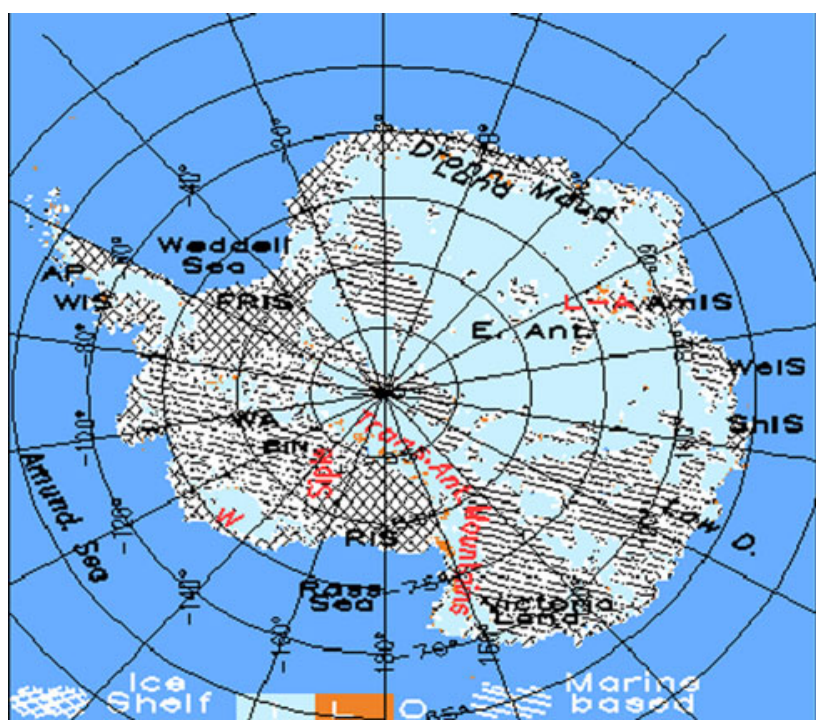

Fig. 1 The Antarctica land-ice-ocean mask based on SeaRISE 5-km resolution digital elevation, ice thickness and bedrock elevation data (Bamber et al. 2009). In the color shading, white is ice, yellow (brown) is bare ground (L) and blue is oceanic grids. The ice shelves are cross-hatched areas; land ice with base under sea level (marine based) is hatched. Note that marine-based ice sheets cover more than $70 \%$ of the ice sheet. For reference in the following discussion, "W" is Mount Waesche and "L-A" is the Lambert Glacier-Amery Ice Shelf system. Some ice shelves, glaciers and seas are labeled: Antarctic Peninsula (AP), Wilkins ice shelf $(W I S)$, Bindschadler ice stream $(B I N)$, Ross ice shelf (RIS), Filchner-Ronne ice shelf (FRIS), Amery ice shelf $(A m I S)$, West ice shelf $(W e I S)$ and Shackleton ice shelf $(S h I S)$

spherical earth coordinate system. Because the geographical location of Antarctica, a projection transformation is used to displace the pole outside the simulation domain. Various remote sensing data and atmospheric/oceanic data from coupled general circulation models (CGCMs) are specified in Sect. 3. The remotely sensed data are primarily for model verifications. The CGCM output provides the atmospheric forcing for SEGMENT-Ice. Section 4 contains the results and discusses the SEGMENT-Ice simulations of the 3D flow field. Model simulated land ice mass losses and features of tabular calving during the past decade are compared with available measurements, and SEGMENTIce predictions are presented of the mass changes for the AIS for the twenty-first century, under a range of future scenarios provided by CGCMs. Section 5 draws conclusions resulting from this study.

\section{The ice model}

\subsection{The SEGMENT-Ice model}

SEGMENT-Ice is a component of an integrated scalable and extensible geo-fluid model (SEGMENT, Ren et al. 
2011a, b). In SEGMENT, the momentum equations are prototyped in the rotating earth reference system. The numerical model is a discretized representation of the governing partial differential equations. The equations are in generalized curvilinear coordinates. In discretizing the model horizontal domain, SEGMENT-Ice takes the earth's curvature into consideration. The horizontal grid is a regular latitude $(\phi)$-longitude $(\theta)$ grid. Uneven spacing in latitude/ longitude allows higher resolution for marginal areas. The governing equations are, in spherical coordinates:

$$
\begin{aligned}
\frac{\partial u}{\partial t} & +\frac{u}{r \cos \phi} \frac{\partial u}{\partial \theta}+\frac{V}{r} \frac{\partial u}{\partial \phi}+w \frac{\partial u}{\partial r}-\frac{\operatorname{tg} \phi}{r} u V+\frac{u w}{r} \\
& =\frac{1}{R \cos \phi} \frac{\partial \Re_{\theta \theta}}{\partial \theta}+\frac{1}{R} \frac{\partial \Re_{\theta \varphi}}{\partial \phi}+\frac{1}{R^{2} \cos \phi} \frac{\partial \Re_{\theta r}}{\partial r}-\frac{g}{r \cos \phi} \frac{\partial r}{\partial \theta}
\end{aligned}
$$

$$
\begin{aligned}
& \frac{\partial V}{\partial t}+\frac{u}{r \cos \phi} \frac{\partial V}{\partial \theta}+\frac{V}{r} \frac{\partial V}{\partial \phi}+w \frac{\partial V}{\partial r}+\frac{\operatorname{tg} \phi}{r} u^{2}+\frac{V w}{r} \\
& =\frac{1}{R \cos \phi} \frac{\partial \Re_{\phi \theta}}{\partial \theta}+\frac{1}{R} \frac{\partial \Re_{\phi \phi}}{\partial \phi}+\frac{1}{R^{2} \cos \phi} \frac{\partial \Re_{\phi r}}{\partial r}-\frac{g}{r} \frac{\partial r}{\partial \phi} \\
& \frac{\partial w}{\partial t}+\frac{u}{r \cos \phi} \frac{\partial w}{\partial \theta}+\frac{V}{r} \frac{\partial w}{\partial \phi}+w \frac{\partial w}{\partial r}+\frac{\operatorname{tg} \phi}{r} u^{2}-\frac{u^{2}}{r}-\frac{V^{2}}{r} \\
& =\frac{1}{R \cos \phi} \frac{\partial \Re_{r \theta}}{\partial \theta}+\frac{1}{R} \frac{\partial \Re_{r \phi}}{\partial \phi}+\frac{1}{R^{2} \cos \phi} \frac{\partial \Re_{r r}}{\partial r}
\end{aligned}
$$

where $t$ is time, $R$ is the Earth's radius, $\theta$ is longitude, $\varnothing$ is latitude, $u$ and $V$ are the horizontal velocity components and $w$ is the vertical velocity component. In Fig. 2, $r$ is the distance from the point of interest to the Earth's center. Here, $R$ is much larger than the ice thickness, so $r$ can be replaced by $R$. Stress decomposition into resistive $(\Re)$ and lithostatic $(L=-\rho g(h-r))$ stresses follows van der Veen and Whillans (1989). Unit vectors are indicated by the superscript ' 0 ' in Fig. 2. The right hand side of Eqs. (1)(3), when expanded, involves viscous terms in the form of vector Laplacians in the spherical coordinate system. When expanded, using Eq. (1) as an example, it becomes:

$$
\begin{gathered}
\frac{1}{R^{2} \cos ^{2} \phi} \frac{\partial^{2} u}{\partial^{2} \theta}-\frac{2 \sin \phi}{R^{2} \cos ^{2} \phi} \frac{\partial v}{\partial \theta}+\frac{2}{R^{2} \cos \phi} \frac{\partial w}{\partial \theta}-\frac{t^{2} \phi}{R^{2}} u \\
-\frac{1}{R^{2}} u+\frac{1}{R^{2}} \frac{\partial^{2} u}{\partial \phi^{2}}-\frac{\operatorname{tg} \phi}{R^{2}} \frac{\partial u}{\partial \phi}+\frac{\partial^{2} w}{\partial r^{2}}+\frac{2}{R} \frac{\partial w}{\partial r}
\end{gathered}
$$

In practice, the calculation domain contains only the media of interest (e.g. ice, or at most limited additional domains that contain ice, such as the basal granular material for land based ice and ocean waters for the ice shelves). The terrain-following sigma coordinate system, $s$, (Fig. 2b), is:

$s=\frac{h-r}{H}$

where $h$ is the distance from the ice surface to the Earth's center and $H$ is the local ice thickness. In SEGMENT-Ice, discretization of the vertical coordinate has irregular spacing, as flow vertical shear is greatest near the bottom, while temperature fluctuations are larger near the ice's upper surface interface between ice and air. Levels are spaced most closely near the surface and the base of the ice sheet.

The Jacobian involved for transferring between two coordinates is, for any function $F$ :
Fig. 2 The general curvilinear system in SEGMENT-Ice. a the spherical rotating earth reference system, (b) the terrain-following sigma coordinate system transfer, and (c) is the stretched vertical grid stencil over Amery Ice Shelf (a)

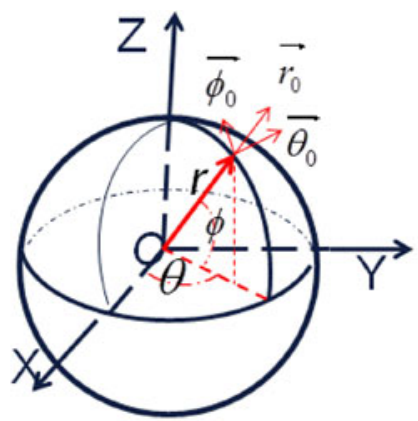

(b)








$$
\begin{aligned}
& \left(\frac{\partial F}{\partial \theta}\right)_{s, \phi}=\left(\frac{\partial F}{\partial \theta}\right)_{r, \phi}-\frac{1}{H}\left(\frac{\partial F}{\partial s}\right)_{\theta, \phi} \Delta s_{\theta} \\
& \left(\frac{\partial F}{\partial \phi}\right)_{s, \theta}=\left(\frac{\partial F}{\partial \phi}\right)_{r, \theta}-\frac{1}{H}\left(\frac{\partial F}{\partial s}\right)_{\theta, \phi} \Delta s_{\phi} \\
& \left(\frac{\partial F}{\partial s}\right)_{\theta, \phi}=-H\left(\frac{\partial F}{\partial r}\right)_{\theta, \phi}
\end{aligned}
$$

Here, $\Delta s_{\theta}$ is short-hand for the $r$-contour's slope in $\theta$ direction, and similarly $\Delta s_{\phi}$ is the slope of $r$-contour surface in the $\phi$ direction. In the new, general curvilinear coordinate system, they are:

$$
\begin{aligned}
\Delta s_{\theta} & =\left(\frac{\partial h}{\partial \theta}\right)_{\phi}-s\left(\frac{\partial H}{\partial \theta}\right)_{\phi} \\
\Delta s_{\phi} & =\left(\frac{\partial h}{\partial \varphi}\right)_{\theta}-s\left(\frac{\partial H}{\partial \phi}\right)_{\theta}
\end{aligned}
$$

The transfer Hessian terms (2nd order derivatives) can be similarly defined. For example,

$$
\left(\frac{\partial^{2} F}{\partial \phi \partial r}\right)=-\frac{\partial}{\partial \phi}\left(\frac{1}{H} \frac{\partial F}{\partial S}\right)-\frac{\Delta s_{\phi}}{H^{2}}\left(\frac{\partial^{2} F}{\partial s^{2}}\right)
$$

The stress $(R)$ is related to strain rate by a rheological relationship (Glen's law). The strain rate, in turn, is calculated from the first order derivatives of velocity. Thus, Eqs. (1-3) have second order derivatives. The Hessian terms (Eq. 11) come into play when making generalized coordinate transform. Five options are available for the lateral boundary conditions in SEGMENT-Ice: Wall (mirror) boundary conditions; periodic boundary conditions; zero-normal gradient conditions; radiative boundary conditions; and specified boundary conditions. For land-based ice, water terminated quick glaciers and ice shelves, the lateral boundary conditions, especially for the flow components, are very different. For example, at the ice shelf front, a force balance with the displaced ocean water is required. At the lower ice-shelf/ocean water boundary, zero lateral stress is assumed and the normal stress is set as the hydrostatic pressure of the displaced water at that depth. For land-based ice, depending on bottom thermal conditions, either no-slip or viscous slip law (MacAyeal 1989) with variable basal drag, or even granular sliding law is employed (see "Appendix"). In SEGMENT-Ice, a time-varying "state-mask" is referred to when setting lateral boundary conditions.

Parameterization of viscosity is critical for ice creeping. At the centers of ice sheets, bottom ice has confining pressures of the order of $10^{7} \mathrm{~Pa}$, not high enough to distort the unit cell lattice but enough to lower the ice melting point by several degrees $(74.3 \mathrm{~K}$ per Gpa, or $\sim 0.66 \mathrm{~K}$ per $1,000 \mathrm{~m}$ of ice loading). SEGMENT-Ice has three improvements over Glen's ice rheological law (Hooke 1981; van der Veen
1999), respectively factoring in flow-induced anisotropy, effects of confining pressure, and granular basal conditions. The flow enhancement by re-fabrication (Wang and Warner 1999) is implemented as older ice, which is farther from the top, and easier to deform.

Ice viscosity depends on temperature, confining pressure, and strain rates. Ren et al. (2011a) proposed a parameterization scheme that considers these factors. The advantage of the scheme is multi-fold: at very small strain rates, it has a temperature- and confining-pressure-dependent limit. In the scheme of Hooke (1981), viscosity must be properly bounded or, equivalently, the maximum allowable deformational ice speeds are bounded, as in most current ice models. In SEGMENT-Ice, two factors contribute to strain rates at the bottom of the ice sheet being larger than the shallow layers: the loading pressure is larger, and temperatures usually are higher and closer to pressure melting point. Ice is shear thinning so that the larger the strain rate, the smaller the viscosity. However, the decrease of viscosity is slower than the increase of strain rate so their product (shearing resistance) increases as strain rate increases. Eventually, the resistive force is large enough to counter gravitational driving stress and steady flow is achieved. At the center of the ice sheet, the bottom ice usually is close to pressure melting. The small ice viscosity cannot generate enough shearing resistance to counter the driving stress from even gentle sloping ice geometry. In this case, the neighbour grids act to balance the residual stresses. Hence, three dimensional, full Navier-Stokes models are needed to depict ice flow more accurately.

Ice viscosity sensitively depends on temperature. SEGMENT-Ice solves a 3-D heat diffusion equation to obtain ice temperature profiles with a changing ice sheet configuration. Latent, sensible and radiative flux divergences at the air-ice interface, internal frictional heating (related to 3D flow structure) within the ice domain, and geothermal heat flux at the ice-bedrock interface are treated as heating sources. The thermal equations are solved using the semiimplicit Crank-Nicolson scheme.

\subsection{Ice stream flow}

For the AIS, slow sheet flow prevails over $90 \%$ of the surface area (Reeh 1968; Rignot et al. 2011a, b), but most flow converges to become fast currents of ice called ice streams near the grounded ice sheet margins. The concentrated ice streams at the pheriphery of ice sheets are manifestations of basal processes ( $\mathrm{T}$. Hughes, personal communication, 2012). SEGMENT-Ice allows a lubricating layer of basal sediments between the ice and bedrock, which enhances ice flow and is a positive feedback for mass loss in a warming climate (MacAyeal 1992; Alley et al. 2005; Ren et al. 2010, Fig. 2). 
The ice streams end as either grounded ice lobes melting on land or floating ice tongues calving into waters. Ice tongues from several ice streams can merge in confining embayments to become floating ice shelves that may also be pinned locally to shoals on the sea floor to produce either ice rumples or ice rises (T. Hughes, personal communication, 2012). As ocean temperatures are lower than around Greenland, there are extensive ice shelves around Antarctica (Fig. 1).

Ice-shelves are floating and the hydrostatic pressure of hundreds of meters of water is non-negligible, considering that the ice shelves have gentle slopes. These buttressing ice shelves provide resistive stress for the adjacent, usually marine-based ice sheet. In SEGMENT-Ice, ocean-ice interactions are parameterized so freezing point depression by soluble substances, salinity dependence of ocean water thermal properties, and ocean current-dependent sensible heat fluxes are included (Ren and Leslie 2011). SEGMENT-Ice has a chemical potential sub-model to estimate the effects of ocean water salinity changes on the grounding line retreat of water terminating glaciers and the erosion of ice shelves. SEGMENT-Ice follows a molar Gibbs free energy bundle in considering phase changes. Melting/refreezing is determined by the chemical potential of $\mathrm{H}_{2} \mathrm{O}$ in both states, across the interface. SEGMENT-Ice estimates ice temperature variations and calculates the fraction of melted ice. When the terminal heat source becomes a heat sink, freezing occurs and ice can extend beyond the initial interface, simulating the advance/retreat of the ice shelf grounding line. SEGMENT-Ice is designed such that when the newly formed ice is less than the dimension of the grid mess, it records the fraction, which melts first when heat flux reverses. If the newly formed ice fills an entire grid, SEGMENT-Ice adjusts its "phasemask" array, to indicate the new water/ice interface. The reverse (melting) process is analogous.

Hughes (2011), among others, has found that the transitions from sheet flow through stream to shelf flow are essentially governed by the longitudinal force balances. The unified physical basis for these transitions is a progressive reduction in the strength of ice-bed coupling, underlining the importance of basal granular material. The movement of glacial ice is achieved by a combination of visco-plastic flow, sliding, and the deformation of underlying basal sediments. Pressure-melted water plays an important role in each of these processes. The 'grade-glacier' theory (Alley et al. 1993) generalizes silt production and transportation as an integrated component of the ice erosion of the glacier bed. It shows that climate fluctuations, by modifying ice surface slope, can affect sediment transport and erosion patterns. This theory directly motivated the present research because the established warming climate may flatten the marginal area of the ice streams surrounding the AIS and therefore encourage the deposition of granular sediments. There are many uncertainties in treating the basal processes in numerical models. For example, why sheet flow turns into concentrated stream flow is not fully understood. A positive feedback from granular rheology may play a role in the flow concentration. Granular material can be widely available under AIS because, during the ice-sheet's history, around the grounding line repeated phase changes between ice and water are very effective mechanisms in producing granular material. The process is several orders of magnitudes faster than uniform weathering by runoff water. To first order, the subglacial geochemical environment consists of finely crushed rocks bathed in ice melt, analogous to flowthrough reactors (Anderson 2006). To evaluate the effects of granular basal material on ice flow, effective grain size and granular layer thickness are needed. Obtaining the granular layer thickness is difficult because, not only the production rates are required, the sub-glacial flow washout rate also are needed. Fortunately, with sufficient surface ice flow observations and known ice temperature distributions, the granular parameters are objectively retrieved by data assimilation approach in the ice model. Here, the basal granular parameters are retrieved from NASA's Making Earth Science Data Records for Use in Research Environments (MEaSUREs, http://nsidc.org/data/nsidc-0484.html), as outlined in the "Appendix".

\subsection{Mass balance}

As the climate warms, increased air temperatures through turbulent sensible heat flux exchange, increase surface melting and runoff. Similarly, changes in precipitation affect the upper boundary input to the AIS. For the 200year period of interest, major ice temperature fluctuations are near the upper surface of the AIS. However, strain rates can be large near the bottom, so SEGMENT-Ice has 81 stretched vertical levels to better differentiate bottom and near surface ice domains (Fig. 2c). The uppermost layer is $0.5 \mathrm{~m}$ thick near the central area of Antarctica, fine enough to simulate the upper surface energy state on a monthly time scale. In SEGMENT-Ice, the total mass loss comprises surface mass balance and the dynamic mass balance due to ice flow divergence.

In SEGMENT-Ice, the total mass loss comprises surface/basal mass balance and the dynamic mass balance due to ice flow divergence. Total mass balance is converted to water volume and is used to calculate the eustatic SLR contribution. A vertical integration of the incompressible continuity equation, with surface mass balance rate and basal melt rate boundary conditions, gives: 


$$
\begin{aligned}
\frac{\partial h}{\partial t}= & -\frac{1}{R \cos \phi} \int_{0}^{1}\left(\frac{\partial u}{\partial \theta}+\frac{\partial V \cos \phi}{\partial \phi}\right) H \mathrm{~d} s-\frac{u_{s}}{R \cos \phi} \frac{\partial h}{\partial \theta} \\
& -\frac{V_{s}}{R} \frac{\partial h}{\partial \phi}+w_{b}+b
\end{aligned}
$$

Here vertical velocity component $w$ is expanded using the continuity equation, assuming incompressible ice. Eq. (14) is the temporal evolution of the surface elevation, or ice thickness as bedrock is unchanged. It varies with velocity fields and boundary sources. In Eq. (14), it is assumed that the Earth's radius is much larger than the ice thickness. The subscripts ' $b$ ' and ' $s$ ' refer to the bottom and upper ice surfaces. The $w_{b}$ term includes the basal melt rate component and $b$ is surface mass balance rate. Changes in ice thickness multiplied by grid area gives the volume ice loss for that grid. The total ice loss is the summation over the entire simulation domain.

The surface mass balance scheme is adapted from the Simulator for Hydrology and Energy Exchange at the Land Surface, known as SHEELS (Crosson et al. 2002). It starts from meteorological conditions (precipitation, near surface air temperature, winds, and divergence of surface radiative fluxes). Surface energy balances are calculated and form the basis on which sublimization, runoff and firn evolution are estimated. For the AIS, sublimation and runoff are very small for the central regions. Katabatic wind entrainment/redistribution is significant throughout and assists in the formation of blue ice areas (BIAs) on the south slopes. At the bottom of ice sheet, once pressure melting point is reached, additional energy input (primarily the convergence of conductive heat fluxes and strain heating) is used to melt ice. The estimation of the melt water depends on bottom topography and the subglacial hydrological system. For example, the central parts of the Eastern Antarctic Ice Sheet typically cannot find a pathway to ocean, which also is the case for the central section of the West Antarctic Ice Sheet (WAIS). Phase changes from solid to liquid are taken into account in the next integration step by re-gridding the simulation domain (e.g. the ice-super cooled water-bedrock configuration). Interested readers are referred to PISM (Martin et al. 2011) and SICOPOLIS (Greve 2005) for their respective treatment of the basal melt scheme. The Polar WRF model (http://polarmet.osu.edu/ PolarMet/pwrf.html) also has an improved version of the snow evolution scheme of (Liston et al. 1999).

\subsection{Model spin-up and improved numerics}

It is critical to obtain a steady flow (in agreement with the ice geometry and temperature regime) before applying the transient climate forcing to project the future state of the ice sheet. We have the following spin-up strategy (Ren et al. 2011a): Starting from zero velocity field at the given present ice geometry and the atmospheric forcing of 1900 (from pre-industrial control runs of climate models). Because we are dealing a full-Navier-Stokes code in combination with a shear-thinning rheological law, it is important to set a suitable asymptote viscosity for grid points with effective strain rate less than $10^{-8} \mathrm{~s}^{-1}$. All rheological relationships proposed are based on experimental shear-strain diagrams. However, because laboratory ice mechanics experiments must be finished at reasonable time span, it currently lack shear-strain diagram extending to very small strain rate regime. We set the viscosity for those 'still' grids $\left(1-T / T_{p}\right)^{1 / 5} \times 10^{14} \mathrm{~Pa} \cdot \mathrm{s}$, with $T_{p}$ being the pressure melt temperature. As integration continues, effective strain rate will be greater than $10^{-8} \mathrm{~s}^{-1}$ and regular parameterization of the viscosity will be activated. Depending on the detailed numeric, the exact number of integrations may vary significantly, however, in general, the bottom layer reaches stability first and the shallower layer reaches steady flow thereafter. Upon reaching a steady flow field, the dynamic and thermodynamic and the evolution of the free surface are solved in a fully thermomechanically coupled manner. Note that even after spinup, atmospheric forcing is updated every month, much larger than the time step of ice dynamics (and thermodynamics) integration, which is on hourly basis.

Because of the ever changing atmospheric forcing and the large inertia of the ice sheet, surface mass balance and dynamic mass balance from existing ice geometry never exactly cancel each other. Our spin-up strategy reflecting the aim of this research: to investigate the total mass balance trend through the historical anthropogenic trend associated with green house gases emissions since 1900 . The above spin-up strategy also implies that the residual trend on glacial time scale is treated as constant. The model verifications are primarily during the current climate conditions (remote sensing era) and projections are for the twenty-first century. As inter-annual and multi-decadal variations from CGCMs are not expected to match those in the real world, only the anthropogenic trend associated with greenhouse gases is believed to be reasonably captured. Note that the projected changes in future AIS conditions driven by CGCM-provided atmospheric conditions only represent the general anthropogenic trends.

Both dynamic and thermodynamic components are subject to the transformations into curvilinear space. The polar singularity is removed in SEGMENT-Ice by a "pole rotation" (Fig. 3) that displaces the pole outside the simulation domain. The pole is rotated $40^{\circ}$ anti-clockwise (Fig. 3, right panel) to place the simulation domain at a computationally more convenient location. There are two important recent improvements in SEGMENT-Ice numerics. The RAW filter (Amezcua et al. 2011; Williams 2009) is adopted instead of the more commonly used Asselin time 
Fig. 3 Antarctica in physical space (left) and rotated into a calculation space (right), polar stereographic projection with standard latitude $70^{\circ} \mathrm{S}$ and central meridian $180^{\circ} \mathrm{E}$. After rotation, the ice sheet is centered at $40^{\circ} \mathrm{S}$ and $90^{\circ} \mathrm{E}$. Cross marks indicate scalars and circles indicate staggered vectors. Color shading is surface elevation $(\mathrm{m})$

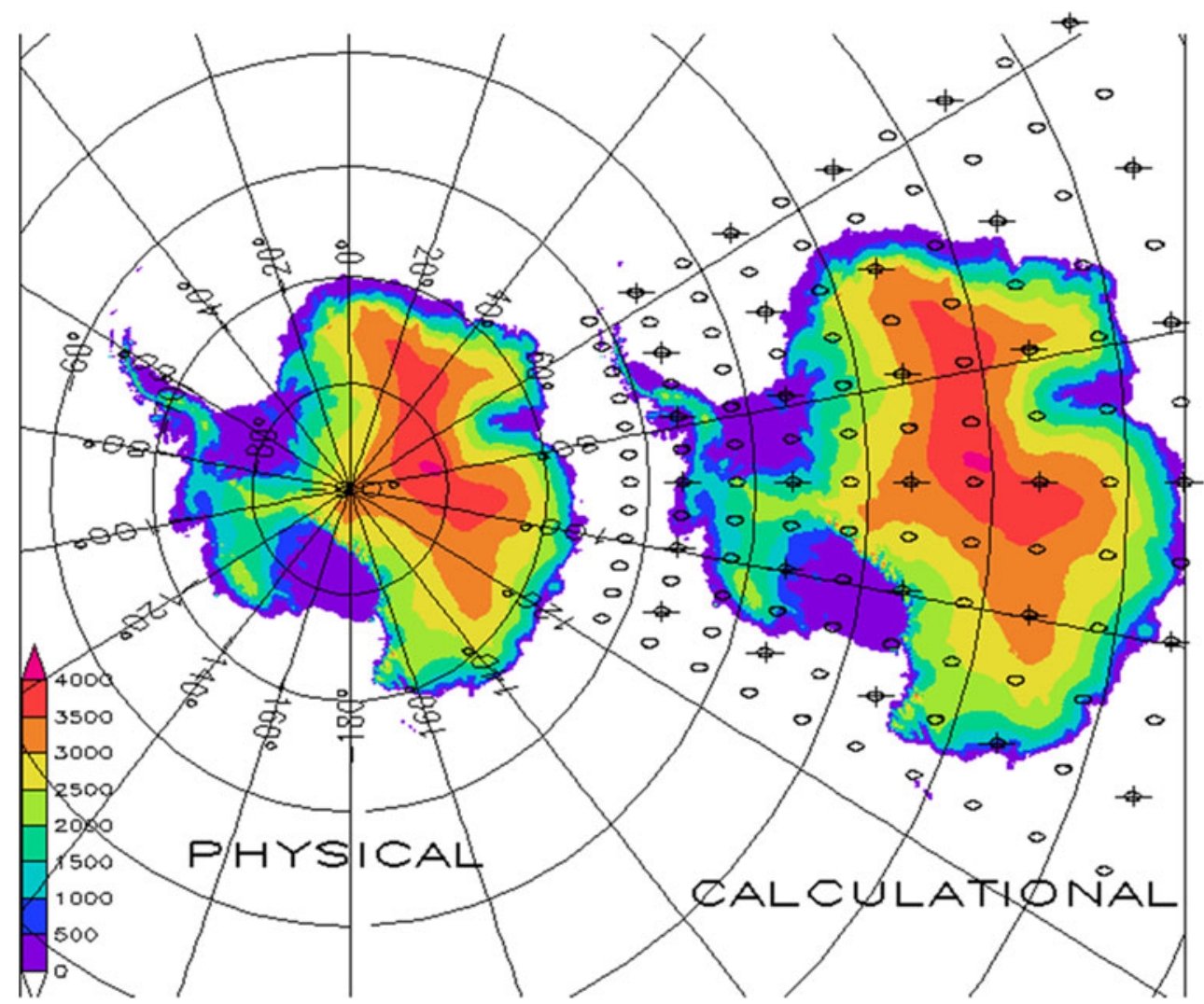

filter. It improves both spin-up and conservation energetics of the physical processes (Paul Williams, personal communication, January 2011). A second improvement is in the optimization procedure of the data assimilation code. A quasi-Newton minimization scheme is used instead of the original conjugate-gradient scheme, as the latter is less robust and less efficient for real, noisy data.

\subsection{The calving scheme}

The above framework and physics are generally applicable to any ice sheet. The calving scheme implemented in SEGMENT-Ice is designed with Antarctica's peripheral ice shelves in mind. The inland crevasses are estimated according the von Mise criteria (Vaughan 1993). In the numerical model, the strain stress transfer follows Jaeger (1969, p. 12). Whether or not a tabular calving occurs is determined according to the "girder approximation", an extension of Reeh (1968) by factoring in flow shear. Because of the relevance for ice sheet evolution, several calving mechanisms have been proposed. Scambos et al. (2004) proposed a hydrologic fracturing mechanism suitable for ice shelves residing in relatively warmer environment, or with seasonal surface melt (e.g., AP). Variants of this mechanism include the basal lubrication of percolated/drained surface melt water. Several studies have also cited evidence of warm ocean waters thinning ice shelves from below (Shepherd et al. 2003; Glasser and Scambos 2008; Vieli et al. 2007), causing rifting and calving of large iceberg chunks. This mechanism has apparent relevance in a warming climate condition (Rignot and Jacobs 2002; Stammerjohn et al. 2008). Based on previous work (Vaughan 1993; Rist et al. 1999; Pralong and Funk 2005), Albrecht et al. (2011) simulated ice fracturing as a continuous process that increases and decreases in response to damage and recovery (Winkelmann et al. 2011). Despite these efforts, the dynamic processes of calving, especially the large, systematic, tabular calving remain poorly understood (T. Hughes, personal communication, 2011) and a prediction of "when calving occurs" never has been successful (D. MacAyeal, personal communication, 2012).

Both the elastic calving mechanisms originated from Reeh (1968), and the growth of ductile cracks (Kenneally and Hughes 2006) examine calving as local processes in the vicinity of the calving front. Ice shelves creep under their own weight. Due to the vertical flow shear (Fig. 4), the upper layers will be stretched more than lower layers (Reeh 1968), so that the ice front is slanted forward, overhanging more and more with time (Fig. 4; Fig. 2b of Martin et al. 2011). The section towards the front thus displaces less water than its weight. This motion cannot proceed without a simultaneous downward bending of the frontal part (e.g., right/north tip end of Amery ice shelf in Fig. 2c). This bending will partially compensate the 


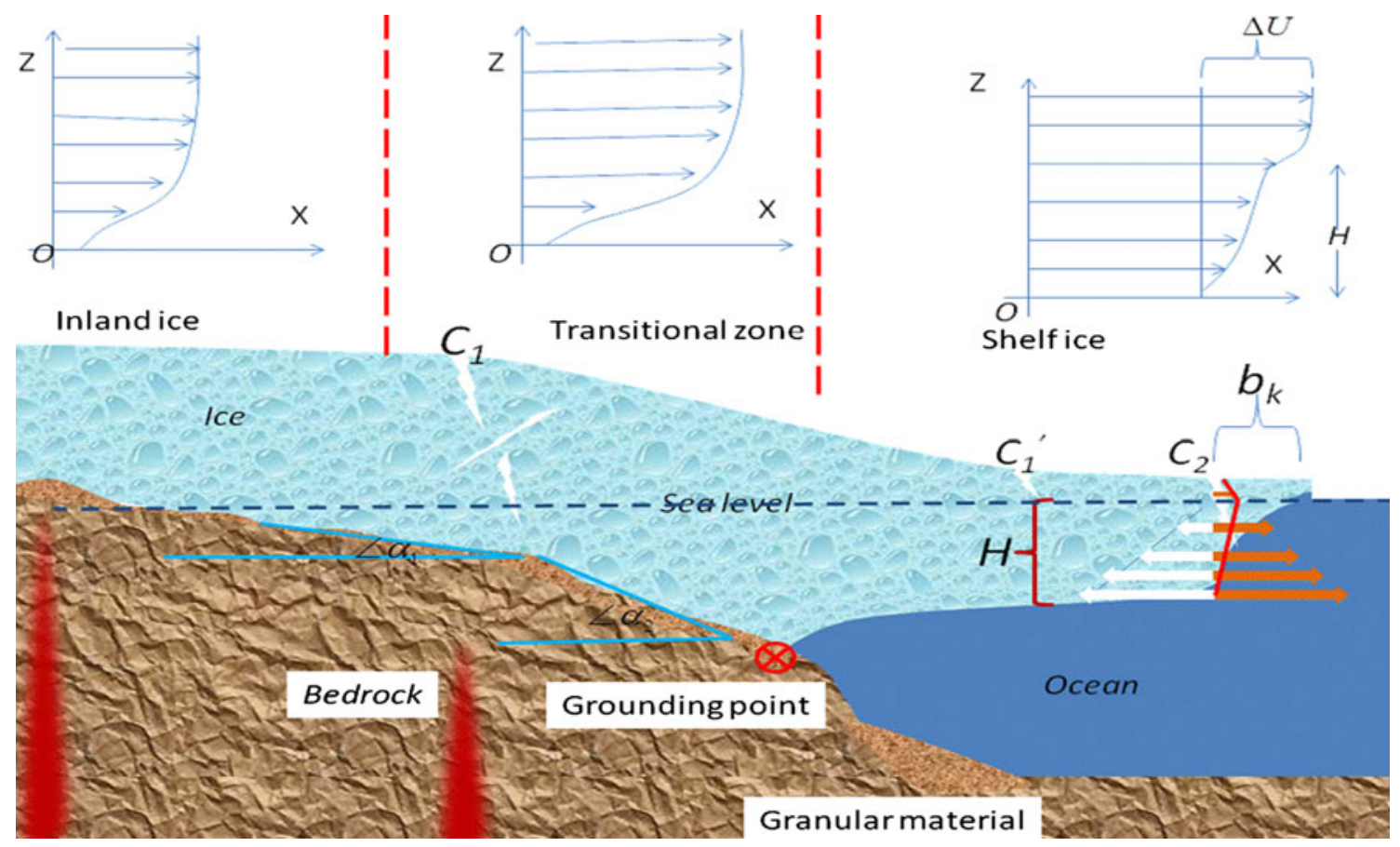

Fig. 4 Inland ice crevassing and shelf ice calving. Ice is brittle and wherever there are strong concentrations of strain rate, it can break $\left(C_{l}\right)$. The upper panels are schematic diagrams of ice profiles, showing the different flow regimes. Note that, due to granular material, the basal velocity is not exactly zero. The acceleration of the ice (to the right) causes the ice to be torn. Inside the ice shelf, the spreading tendency is restrained mainly by longitudinal stretching (along flow stress). Ice shelves thin by creep thinning. The negative vertical strain rate (compression) causes a horizontal divergent (positive) strain rate. The ice shelf's velocity increases toward the calving front as determined by the spatial integral of the horizontal strain rate. In the diagram, white bulk arrows are stress (hydrostatic pressure) on the right side of the calving front exerted by the ocean, decreasing to zero at sea level. The red bold arrows are static stresses exerted on the left side of the front, decreasing linearly to zero at ice

imbalance of gravity and buoyancy of the frontal section. However, if there is no pinning point, the bulk of this imbalance is supported by the inland neighboring section by submerging more than enough to support its own weight. The submerging geometry of ice shelf is thus flowdependent. A 'non-local' calving scheme is proposed that considers calving as a function of ice shelf thickness, temperature, and flow vertical shear.

Figure 4 illustrates the iceberg calving in SEGMENT-Ice. Although the shelf as a whole is in near hydrostatic balance with the ocean waters, the flow structure inside the ice shelf determines that it is a dynamic scenario of advancing-thinning-breaking, from groundling line toward the calving front. "Along-flow spreading" is believed the dominant control on ice shelf calving (Thomas 1973; Alley et al. 2008; Winkelmann et al. 2011). Ice shelves spread under their own weight and the imbalance pushes at the calving front and around the grounding line. According to Reeh (1968), as a upper/sub-aerial surface. The red curve is the net horizontal stress, which reaches maximum at sea level. Hence the vertical variation of horizontal shear and the vertical profile of the velocity have a turning point at sea level. The diagram of the ice shelf is partially adapted from T. Hughes via R. Bindschadler (personal communication, 2011). The vertical profile of horizontal ice velocity field determined that there will be a "mushroom" shaped spread section that are out of hydrostatic balance with the ocean water (although the bulk of the shelf section is in hydrostatic balance with ocean waters). There is a limit of the length of this section before it breaks off from the main body of the shelf ( $b_{k}$ in the diagram). This length is regularly approached to finish a systematic calving (Eqs. 15, 16). There are random components in the calving processes, such as hydrofracturing (Scambos et al. 2000; Doake and Vaughan 1991)

result of the horizontal compression, the geometry is an anvil shaped outreach at the calving front (Thomas 1973; Hughes 1992). The length of this portion is limited by the tensile strength of ice $(f=2 \mathrm{Mpa}$ at present for marginal regions of the Ross Ice Shelf), the ice thickness $(H)$ and the ice creeping speed. As seen in Fig. 4, while the bulk of the ice shelf is in hydrostatic balance with ocean water, this small girder-like part is not. Even with no oceanic melting, there is a limitation to the length of this part $\left(b_{k}\right)$, given by:

$b_{k}=\left[f D_{T} H /\left(3 \rho_{i} g\left(1-C_{T} \rho_{i} / \rho_{w}\right)\right)\right]^{0.5}$

where $\rho_{w}=1,028 \mathrm{~kg} \mathrm{~m}^{-3}$ is the density of sea water, $\rho_{i}$ is the density of ice, $g$ is gravitational acceleration, $C_{T}$ is a factor taking tidal and sea wind swelling into consideration, and $D_{T}$ is a unit-less factor measuring the ratio of ice flow shear $(\Delta U)$ to surface ice velocity. Apparently, $D_{T}$ is a function of ice temperature. Ice density varies according to the formula in Thomas (1973). Assuming the mean ice 
creeping speed at the calving front is $U$ and its vertical shear is $\Delta U$ (Fig. 4), then the average calving period is given by:

$\tau \approx b_{k} / U$

Equation (15) is a relationship for a steady, systematic background calving rate. It is a physically based relationship between rift opening (and thus tabular-iceberg calving) and glaciological stresses (Joughin and MacAyeal 2005). As the ice shelves are dynamic, ice moves constantly toward the calving front. The cracks/rifts upstream $\left(C_{l}\right.$ in Fig. 4$)$ caused by stress larger than maximum tensile strength (i.e., at the flanks of an ice stream), or by hydrologic-fracturing, can eventually be advected toward the calving front $\left(C_{1}^{\prime}\right)$. From Eq. (15), calving is ice thickness-dependent. For the hydrologic-caused fracture, the water can deepen cracks and wedge in the ice shelf (Scambos et al. 2004), reducing the local thickness. Downstream advection of the ice cracks makes the calving process less regular and less periodic. For Antarctica, the two largest ice shelves calve more systematically, and smaller fringing shelves calve more randomly.

This calving scheme includes both geometry and material properties (e.g., thickness, temperature and density), but also accounts for flow features (i.e., vertical flow shear that represents along-flow ice shelf spreading). Equation (15) explains why some very fast flowing ice streams do not have extension sections as ice shelves. Although the surface elevation gradients drive the ice flow, fast flowing ice streams that tend to have banded crevasses often are collocated with sudden bedrock gradient changes. The fast flowing nature of the ice stream provides limited time for compression healing of ice shelves (Hughes 2002) when the ice is on water while still connected to the land-ice. These large systematic crevasses greatly reduce the limiting length for systematic calving and discharged ice is removed by ocean water (or collision with passing icebergs), as icebergs, shortly after leaving the grounding line transition zone.

According to this hypothesis, accompanying a calving event, both the tabular iceberg and its parent ice shelf will adjust their respectively displaced sea water volumes, inevitably displacing sea bed sediments. Thus, the proposed formula assists paleo-reconstruction of major historical calving events. As tabular calving is a low frequency phenomenon, there are insufficient direct observations to identify trends or to draw reliable conclusions about whether production of the giant icebergs in 1985 and 2000 signifies changes of the AIS within a warming climate.

\section{Input and verification data}

SEGMENT-Ice requires initial conditions and static inputs, such as ice thickness, free surface elevation, and the three- dimensional ice temperature field at the initial time of integration. These data are obtained from the SeaRISE project (http://websrv.cs.umt.edu/isis/index.php) at $5 \mathrm{~km}$ horizontal resolution (Fig. 1). Surface topography and bedrock topography are originally from Bamber et al. (2001). Geothermal heat flux is originally from Shapiro and Ritzwoller (2004). Geothermal heat flux is a boundary condition for the ice temperature solver and is assumed constant during the transient climate change period. There are 5 different grid types reflecting the ice-water-land configuration: ice covered ground above sea level; land ice with basal elevation below sea level, known as marine ice sheets (Thomas et al. 2006); bare ground; ice shelves, and oceans. At $5 \mathrm{~km}$ resolution with a South Polar Stereographic Projection, there are 288,393 grids of land ice with bases above sea level, covering $8,534,101 \mathrm{~km}^{2}$ of ice of total volume of $16,097,579 \mathrm{~km}^{3}$, and 171,184 marine based land ice grids (ice area 5,163,998 and 12,227,874 $\mathrm{km}^{3}$ ). Ice shelves cover $3,531,483 \mathrm{~km}^{2}$ and about $1,733,206 \mathrm{~km}^{3}$ of ice. Considering area alone, there are $2.723 \times 10^{7} \mathrm{~km}^{2}$ of ice coverage and only $1.7 \%$ is bare ground.

At $5 \mathrm{~km}$ resolution, the largest slope angle represented by the grid stencil is about $14^{\circ}$. This is a good representation of the surface topography except for marginal areas such as the rugged valley of Lambert glacier and the Transantarctic Mountains. At these locations, model topography is smoother than reality. Consequently, at the edge of the simulation domain, the ice velocity that satisfy the momentum equation are usually not large enough to satisfy the ice flow fields required by surface mass balance. A compromise is made at spin-up. The ice thickness reduces to zero not at the full grid length, but at a distance less than the grid length. After spin-up, the flow-induced mass loss matches the surface mass balance to within $15 \mathrm{~km}^{3}$ for the entire AIS. During spin-up, atmospheric forcings are the pre-industrial control simulations of the CGCMs. The end time of the spin-up is year 1900. The bottom geothermal distribution is constant over the following 200-year simulation.

The SLR contribution from Antarctica is from the total mass balance: that is, input minus output. Atmospheric temperature, precipitation and near surface radiative energy fluxes are key factors for the future total mass balance of the AIS. Three independent CGCMs (MPIECHAM, NCAR CCSM3 and MIROC3.2-hires, see http://www-pcmdi.llnl.gov/ipcc/about_ipcc.php) are chosen for their relatively fine resolution and for providing all atmospheric parameters required by SEGMENT-Ice. Their projections of precipitation and temperature, two key factors affecting ice sheet mass balance, produce a large spread in the multi-model assessments (Chapter 10, IPCC AR4) by 2100. In addition to atmospheric parameters, investigating the ice ocean interactions, the ocean flow 
speed $(\vec{V})$, potential temperature $(T)$, salinity $(S)$, and density $(\rho)$ also are needed. The CGCMs ocean model output at depths $0,10,20,30,50,75,100,700$ and 1,000 m depths are interpolated to SEGMENT-Ice grids. As $70 \%$ of the West Antarctic ice is marine-based (that is, grounded below sea level, Fig. 1), the ice-ocean interaction is persistent and can cause instabilities (Shepherd and Wingham 2007).

GRACE has provided monthly measures of Earth gravity changes since March 2002 (Tapley et al. 2004), and a decade-long time series is available. This study uses the second data release (GRACE RL02), providing spatial resolution of $\sim 100 \mathrm{~km}$, with PGR effect removed using the method of (Ivins and James 2005). These data can verify our model estimates of Antarctic ice sheet mass loss, the spatial distribution as well as absolute amount. The focus is on the AIS sea level contribution. Mass redistributions are limited to land ice, ice shelves and oceans. Other components, such as land reservoirs, nonpolar glaciers and ice caps and atmospheric moisture content are assumed unchanged. For example, phase changes at the interface of ice shelf and ocean, precipitation changes over ice shelves both are mass relocations between ocean and shelf ice and do not in principle affect sea level so they cannot be sensed by GRACE satellites. In contrast, ice discharged from West Antarctica to the Ross Ice Shelf through the Siple coast is a mass relocation from land ice to shelf ice and has sea level consequences.

Remotely sensed ice velocities are limited to the upper surface. The ice motion is now measured using Interferometric Synthetic-aperature Radar (InSAR) data from the Canadian Space Agency Radarsat-1 satellite (2000-2009, Jezek 2008), Japanese Space Agency phased array 1-band synthetic aperture radar palsar (2006-2009) satellite, and the European Space Agency Earth Remote Sensing satellites ERS-1/2 (1992, 1996, Rignot et al. 2011a, b). This study involves two surface ice velocity datasets: Radarsat1 SAR sensor via Modified Antarctic Mapping Mission (MAMM, Jezek 2008, http://bprc.osu.edu/rsl/radarsat/data/ ) and MEaSUREs. The latter reduced the former's polar hole by introducing interferometric synthetic-aperture radar data from multiple satellite missions. There apparently involves uncertainty in cross comparisons and integration over extended time period (MEaSUREs was released very recently but the data are around the same period as MAMM). In contrast, MAMM has the advantage of control points distributed about the entire continent as well as having a single measurement campaign from which to compile the data. It is based on these considerations, we retrieve basal parameters using MEaSUREs and verify model simulated flow fields with MAMM data alone.

\section{Results and discussion}

Here, the available horizontal velocities from MEaSUREs improve the modelled 3-D ice flow fields through improved parameter settings for basal granular parameters in SEGMENT-Ice ("Appendix"). With improved model parameters, SEGMENT-Ice is driven by meteorological parameters to estimate present conditions and to make projections of future total mass loss of the AIS. This section is divided into two main parts: SEGMENT-Ice simulations of present, mainly 2000-2010; and SEGMENT-Ice simulations from 2000 to 2100 under a range of future climate scenarios. The first sets of simulations are compared with available observational data.

\subsection{Present SEGMENT-Ice simulations (2000-2010)}

In contrast to its Greenland counterpart, the AIS does not experience strong seasonal melting, and lacks a welldeveloped ablation zone like those at the periphery of the Greenland Ice Sheet (Ren et al. 2011a, b). However, ablation does take place, as is evident from the widespread occurrence of BIAs, where divergent ice flow works in synergy with katabatic winds that removes the firn layer and leave blue glacier ice exposed. Moreover, extensive melt water streams have been detected in coastal East Antarctica and large melt ponds frequently occur over AP ice shelves (Liston et al. 1999; Scambos et al. 2003). Stake measurements detected snow ablation over the Lambert Glacier catchment (Wen et al. 2006), and Dronning Maud Land (Watanabe 1997). The overall AIS mass balance is such that the surface mass balance accumulation over most of the ice sheet is balanced by flow divergence. Divergence at the ice sheet-ocean interface is manifested as calving.

\subsubsection{Surface mass balance}

According to van den Broeke et al. (2006), spatial variations of surface mass balance over the AIS are large, varying between $5,368 \mathrm{~mm} / \mathrm{a}$ at $\mathrm{AP}\left(-63.5^{\circ} \mathrm{W} ; 64.58^{\circ} \mathrm{S}\right)$ and $-38.5 \mathrm{~mm} / \mathrm{a}$ at central East Antarctica $\left(24.61^{\circ} \mathrm{E} ; 72.67^{\circ} \mathrm{S}\right)$. Solid precipitation is the dominant positive contributor to the surface mass balance. However, at an effective resolutions of $\sim 40 \mathrm{~km}$ longitude at the Antarctic coast, CGCMs simulated precipitation is unable to represent ablation areas of size $4,000 \mathrm{~km}^{2}$ (Fig. 5a). This is true for SEGMENT-Ice estimates of surface mass balance, using climate-modelprovided wind speed, surface radiative energy balance components, precipitation and near surface air temperature, even though ice surface temperature is provided at $5 \mathrm{~km}$ resolution ( $\sim 2 \mathrm{~km}$ of longitude at the Antarctic coast) by the ice model. A downscaling scheme assimilates the van 
(a)

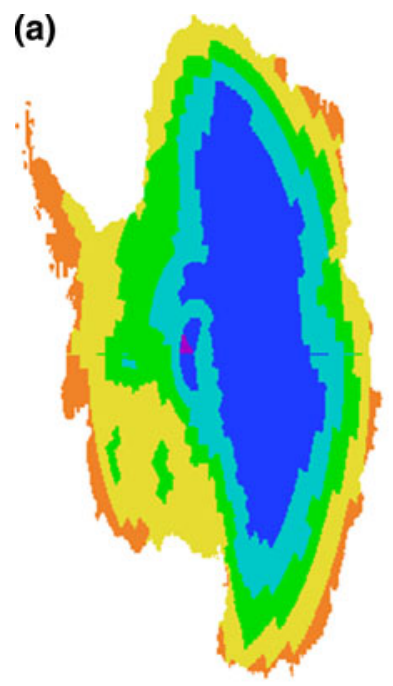

(b)

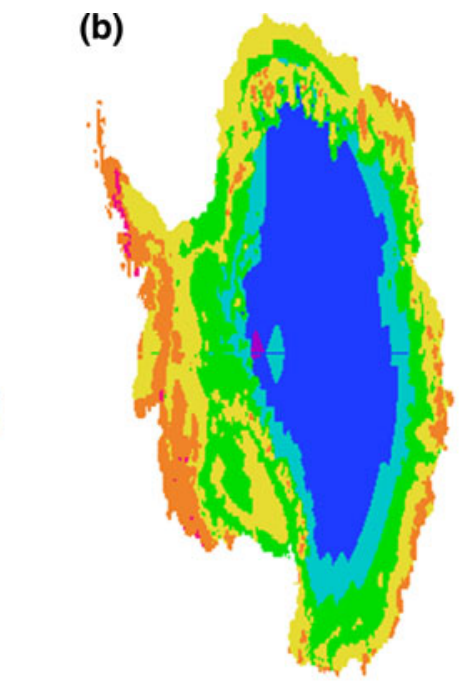

(c)

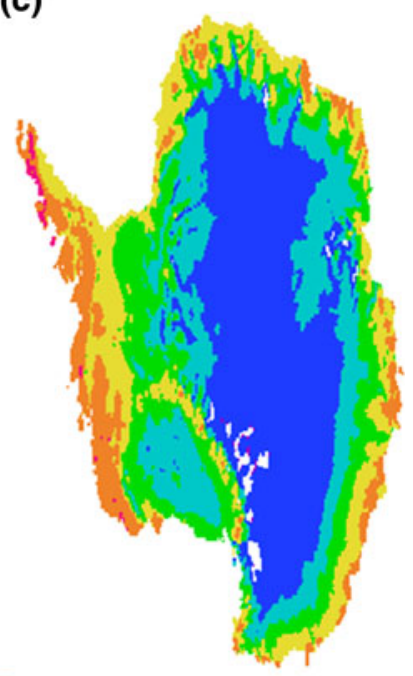

5

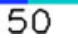

Fig. 5 a is the precipitation $(\mathrm{mm} / \mathrm{a})$ from MIROC-hires for year 2000. Panel (b) is surface mass balance $(\mathrm{mm} / \mathrm{a})$ estimated by SEGMENT-Ice, down-scaled using van den Broeke's surface mass balance model. $\mathbf{c}$ is the van den Broeke et al. (2006) surface mass balance estimate for year 2000. b is used together with the dynamic mass changes to estimate total mass loss over Antarctica. Although the dominant positive contributor to surface mass balance, the Antarctic solid precipitation map from this high-resolution climate model still cannot represent ablation areas $<4,000 \mathrm{~km}^{2}$. Moreover, the climate models fail to simulate heavy precipitation, such as the $\sim 5,000 \mathrm{~mm}$ area on the Antarctic Peninsula

of ice shelves have relatively slow ice flow. Except near the calving front, where ice velocities can reach $1,500 \mathrm{~m} / \mathrm{a}$, ice shelves typically have flow speeds of about $100-500 \mathrm{~m} / \mathrm{a}$, with flow direction primarily pointing to the sea. The Ross Ice Shelf flows seaward but is horizontally confined by the rocky coast of the Transantarctic Mountains. Ice flows off the rocky coast and converges onto the Ross Ice Shelf. Snow precipitation and ice convergence are balanced mostly by melting at the ice-water interface and iceberg calving, as surface melting and sublimation are limited in this high latitude region.

On a smaller scale, the local topography also has a flow signature. For example, the flow radiates away from Mount Waesche in Marie Byrd Land ("W" sign in Fig. 1). Some flow contributes to the Pine Island ice stream, and the southern flow branch feeds the source region of the Ross Ice Shelf. Another example is the convergent field for the area confined by the $3,500 \mathrm{~m}$ elevation contour (upstream of the Lambert Glacier). This BIA area has a negative surface mass balance (not shown). The converged ice flow balances this mass loss, thereby maintaining near balance.

The AP, the saddle region upstream of Pine Island glacier, the lower slope along the Transantarctic Mountains (ice shelves side), the northwest extension of Victoria land (Drygalski Ice Tongue), the West Ice Shelf and the lower stream of Amery Ice Shelf all have large velocity cores, for different mechanisms. The AP has larger ice speeds because the ice temperature is higher. The Transantarctic 
Mountains and Lambert Glacier have large ice velocities primarily because of their topographic slopes. However, depending on ice thickness, the divergence rate is not necessarily large at the steep valley slopes. Complex topography also explains the disordered ice flow structure over the West Antarctica sector, between $90^{\circ} \mathrm{W}$ and $140^{\circ} \mathrm{W}$ (facing the Amundsen Sea). However, the relative large flow speeds over the saddle region (centered at $80^{\circ} \mathrm{S}$; $110^{\circ} \mathrm{W}$ ) are due partly to the local maximum of geothermal heat flux of $\sim 120 \mathrm{~mW} / \mathrm{m}^{2}$. This significantly raises the basal ice temperature and reduces the ice viscosity, thereby increasing the ice speeds.

SEGMENT-Ice simulates reasonably well the velocity profiles for various ice-bedrock-water configurations. Figure $6 \mathrm{~b}$ shows vertical $u$-component velocity at the middle of West Antarctica (characteristic inland ice, "+" in Fig. 6a), on shelf but close to transition zone (circle) and shelf near the ice/ocean front (circle-with-vertical-bar) on Ross Ice Shelf. The inland ice shows a characteristic shear-

(a)

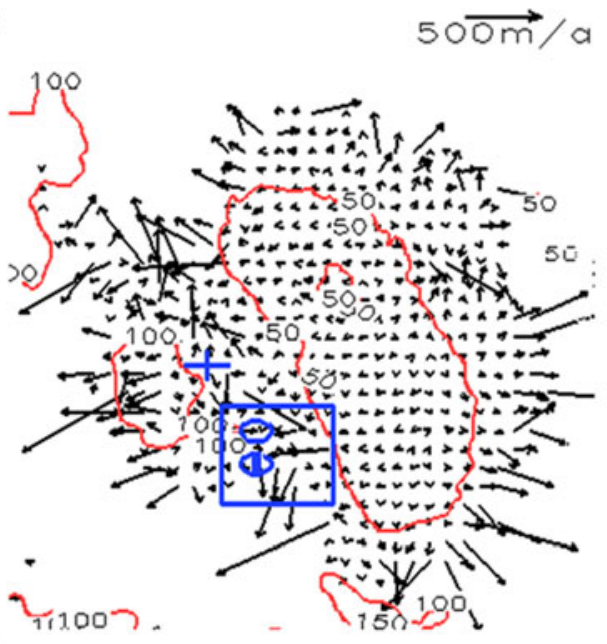

(c)



thinning profile, and shearing resistance locally balances most of the gravitational driving stress. Velocity profiles taken from ice shelves are almost vertical and have small vertical shear (as shown schematically in Fig. 4). The vertical shear increases from the transition zone towards the ice/ocean front. Although the magnitude of this shear is only tens of meters per year, it is critical for tabular calving. Profiles at locations with granular basal sliding are similar to inland ice but have a constant shift superimposed on the non-sliding profile.

The areas with largest ice flow speed are coastal valleys (e.g., $40^{\circ} \mathrm{W}$ and facing Weddell Sea; the marginal belt between 130 and $150^{\circ} \mathrm{E}$ ) and the foothills of the Transantarctic Mountains. An area of coherent large flow speeds is the West Antarctica ice sheet facing the Amundsen Sea. Due to complicated bottom topography, there are interlaced areas with very small flow speeds or stagnant areas, indicating that its surface topography may be very dynamic. There are many obstacles between the (b)

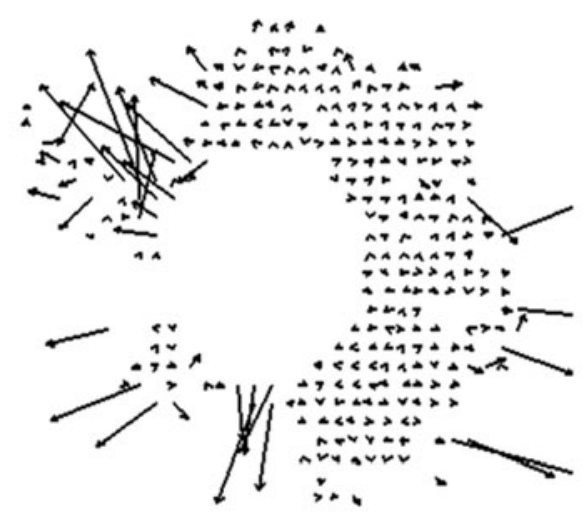

(d)
Fig. 6 SEGMENT-ice simulated present ice flow fields (m/a). a is surface level. Overlain are geothermal heat fluxes $\left(\mu \mathrm{W} / \mathrm{m}^{2}\right)$. b is MAMM measured surface velocities. $\mathbf{c}$ is vertical u-velocity component profiles at the cross mark (inland ice), circle mark (shelf ice close to transitional zone) and circle-with-vertical-bar mark (shelf ice close to ice/ocean front) of (a). At the cross mark, ice extends from $114 \mathrm{~m}$ elevation to $2,100 \mathrm{~m}$. This velocity shape is characteristic of shearthinning fluid. Velocity profile within the top $450 \mathrm{~m}$ are shown for the two locations on Ross Ice Shelf. $\mathbf{d}$ is a zoomed-in view of the Ross Ice
Shelf (blue rectangle in panel (a)) surface ice speeds (color shading). There is a stagnant area on the Ross Ice Shelf $(<100 \mathrm{~m} / \mathrm{year})$ of thicker ice at the central part off the steep Trans Antarctic Mountain coast. Outside this stagnant region, the ice speeds accelerate toward the ice/ocean front and can reach 2,000 m/year at the calving front. The "islands" of low ice velocity get pinched shut a short distance from ice rises. The ice rises are of apparent dynamic cause (flow convergence cause thickening) 
fast and slow flow areas and stagnant ice flow likely causes an area of considerable thickening reaching $\sim 1 \mathrm{~m} / \mathrm{a}$ in elevation changes. We also examined a vertical crosssection along the Siple coast (Figure not shown) of velocity magnitude. The maximum velocity cores are mid-slope. Ridges and valley bottoms generally creep slower. Five concentrated ice streams are clearly identifiable. This agrees with Joughin and Tulaczyk (2002), who found that, among the 6 major ice streams of the Siple coast, ice streams C (Kamb Ice Stream) and F (Echelmeyer Ice Stream) are thickening. The average thickening rate for ice stream $C$ reaches $\sim 14 \mathrm{~cm} / \mathrm{a}$, which is about equal to the total annual accumulation, while neighbouring ice streams exibit slight mass losses. Figure $6 c$ is a zoomed in at the Ross Ice Shelf. The first counterintuitive feature of the flow is that, rather than accelerating all the way down to the calving front, only close to the calving front, this feature is salient. Actually, immediately south of the Byrd Glacier discharging route, there is a relative large stagnant area on Ross Ice Shelf of flow magnitude generally less than $200 \mathrm{~m} / \mathrm{a}$. The ice thickness of this region is relatively thicker than the surrounding area. Although the ice discharging off the Transantarctic Mountain hills are of larger speed, the ice convergence rate is not significant because of the ice thickness on those steep slopes are much smaller $(<100 \mathrm{~m})$, except Byrd Glacier, which has 3,000 m thickness before afloat. The flow signature from Byrd Glacier is very clear on Fig. 6c. The strip of ice-rises (labelled) show clear features of "islands" of low ice velocity getting pinched shut a short distance from ice rises. The relative thick ice thickness clearly results from ice flow dynamics.

From the flow direction (for clarity, the $5-\mathrm{km}$ grid is degraded to a $40 \mathrm{~km}$ grid for plotting purpose in Fig. 6a), the Ross Ice Shelf primarily is fed from West Antarctica, through the Siple coast. The Ross Ice Shelf is a buttress hindering flow through the Siple coast. Ice speeds increase by $2 \%$ if the ice shelf is completely removed and everything else the same as present. A sensitivity experiment with prescribed ocean temperature under the Ross shelf indicates that if the temperature is lowered by just $2^{\circ}$, it freezes completely within three thousand years. Thus, the ocean temperature is critical for the future evolution of ice shelves.

Regarding the formation of BIAs, van den Broeke et al. (2006) proposed that ice flows slowly through an ablation area, favourable for the removal of the firn layer. This explains that BIAs are usually found in the vicinity of rocky crops that obstruct the ice flow (e.g., along the Dronning Maud Land coasts), resulting in very low ice velocities. Therefore, enough time is available to remove the firn layer. While clearly being an area of negative surface mass balance, BIAs usually are in approximate mass balance. Katabatic winds typically are in the same direction as the ice flows. In the windward direction (of outcrops), removal of the snow/firn by katabatic winds is the primary component of the surface mass balance. At the same time, slowing of the ice flow implies a mass convergence that compensates for the ice mass loss. The situation in the leeward direction is analogous.

Simulated ice flow velocities were compared with InSAR observations for three glacier systems: the Thwaites and Pine Island Glaciers east of the Ross Ice Shelf and the Drygalsky ice stream west of the Ross Ice Shelf. For the Thwaites and Pine Island Glaciers, simulated maximum speeds are close to observations (Thwaites Glacier at $2,300 \mathrm{~m} / \mathrm{a}$ and at the core of Pine Island Glacier $\sim 4,000 \mathrm{~m} / \mathrm{a})$. However, for the Drygalsky ice tongue, the transectional direction covers only four $5-\mathrm{km}$ grids, which is insufficient to represent the ice geometry adequately. Consequently, modelled maximum speeds are only half those observed speed (400 m/a vs. 790 m/a). The point-to-point correlation of flow directions is close, with a root mean squared error of less than $0.7^{\circ}$. The model simulated surface flow field at Lambert Glacier-Amery Ice Shelf system ('L-A' in Fig. 1) is compared with SAR mosaic composites from $\mathrm{Yu}$ et al. (2010). Agreements are high for both flow speed and direction (correlations are both $\sim 0.9$ ). We would also like to caution that flow features (and ice geometry features as well) on sub-km scales are expected to be highly variable. For example, due to its northern location, AP around Deception Island experiences significant summer melting. From the InSAR digital elevation map provided by MAMM project, SEGMENTLandslide (a version of SEGMENT developed for landslides) indicates that this area is a locality prone to avalanches. Smaller $(200 \mathrm{~m})$ scale flow features from InSAR measurements are also possibly the result of the random variability present in the atmospheric forcing. Thus, only flow features at $>5 \mathrm{~km}$ resolution are expected to be climatologically informative. Surface melting is limited to below 1,200 $\mathrm{m}$ for East Antarctica and reaches 1,500 m for West Antarctica partly because ice flow in East Antarctica advects colder ice than over West Antarctica.

From Eqs. (15) and (16), accurate full 3D velocities are required for an accurate estimation of systematic tabular calving. Unfortunately, we lack direct measurements of ice creeping speeds at depth to validate model simulations. The dynamic components of the mass balance are major terms in the total mass balance over the AIS. Thus, if SEGMENTIce's simulation produces a present day mass loss rate (Fig. 7a) comparable with direct observations, such as the GRACE measurements, more confidence can be placed on SEGMENT-Ice's full 3D ice velocity projections. One degree lat/lon resolution GRACE measurements from April 2002 to January 2009, with the PGR effect removed, are used to estimate a mass loss rate for land-based ice (Fig. 7b). Coupled ocean-atmospheric climate models have difficulties 
Fig. 7 a is SEGMENT-Ice simulated geographic distributions of rates of surface elevation changes over Antarctica between 2003 and 2009 (m/a equivalent water thickness change). b is GRACE ice mass change rate over the same period. The post glacial rebound (PGR) is removed using the method of Ivins and James (2005). A decorrelation filter and a $300-\mathrm{km}$ Gaussian smoothing have been applied to the raw data

\section{Surface elevation change (2009-2003) (m/yr)}

(a)



(b)



GRACE OBS in reproducing the phases of observed interannual and decadal climate variations. Thus, they cannot be used as climate forcing for SEGMENT-Ice model validation against observations on interannual to decadal scales. More realistic climate forcing is provided by the NCEP/NCAR reanalyses (Kalnay et al. 1996), which, among other databases such as NCEP2, ERA-40 and Era-interim, are widely used in climate research. To examine the credibility of SEGMENT-Ice mass loss rate estimates, the reanalyses were merged with atmospheric forcing provided by CCSM3 from 1948 to 2009. SEGMENT-Ice provided highly detailed spatial distribution patterns of elevation changes than GRACE. For example, GRACE shows a mass loss centered on West Antarctica. SEGMENT-Ice indicates that it is the coastal part that lost most of the mass. The Whitmore Mountains actually gain significant amount of mass during the 6 years. Despite the very different resolutions, the modeled and observed total mass loss rates are very close to each other: $\sim-180 \mathrm{~km}^{3} / \mathrm{a}$ (land ice only, excluding the shelf area as GRACE cannot detect mass changes for the shelf area). This is an indirect verification of the model fidelity of the AIS's 3-D modeled ice flow field. Limited by spatial resolution, GRACE cannot provide detailed geographical patterns of mass loss. Dividing the simulation into East Antarctica and West Antarctica, along the $180^{\circ} \mathrm{E}$ longitude, gives mass loss rates during the 2002-2010 of 110 and $50 \mathrm{~km}^{3} / \mathrm{a}$ by GRACE and 130 and $55 \mathrm{~km}^{3} / \mathrm{a}$ from the model simulations.

\subsubsection{Model calving}

Calving is a low-frequency phenomenon, with a short historical record compared with the low frequency of such events, except for the surrogate records of sediments (S. Jacobs, personal communication, 2011). Direct observations of tabular icebergs are available only for the remote-sensing era. The National Ice Center (http://www. natice.noaa.gov/products/antarctic_icebergs.html) provides the locations of all major Antarctic icebergs. The data were sorted to obtain the birthplaces of the icebergs of size larger than $40 \mathrm{~km}^{2}$. The times of calving also are recorded. The coast of the AIS is divided into 20-degree longitudinal bins. The calving events in each longitudinal bin are counted for the period 1996-2009 and the occurrence frequencies are estimated as the total number of calving events divided by the number of years, in this case 14. The model simulated calving frequency is compared with observations (Fig. 8). The apparent underestimation for the $40-80^{\circ} \mathrm{W}$ sector (containing the F-R Ice Shelf) largely occurs because the model cannot simulate the calving events around the AP region limited by current ice thickness and surface elevation data resolutions. Modeled calving rates for other coastal regions are close to reality. It is clear that the exact calving timing and sizes of the icebergs are not well simulated at present. To improve timing simulations of calving events, it may be necessary to include triggers such as pressure perturbations caused by long waves (compared with $b_{k}$, otherwise cancellations are significant between positive and negative phases and net pressure in the vertical direction is small), tides, tsunamis, and collisions with passing icebergs, as suggested by Alley et al. (2008) and more recently partially proved valid by Bromirski et al. (2010). Further improvements of the results, higher resolution ice and bedrock geometry data (on sub-kilometer scale) are needed for the entire AIS, not only the peripheral areas, as initial seed cracks are difficult to capture for eastern Antarctica. As the modified von-Mise criteria are uniformly applied to the AIS, the present DEMs of eastern Antarctic are not sufficiently as detailed as the WAIS. This 


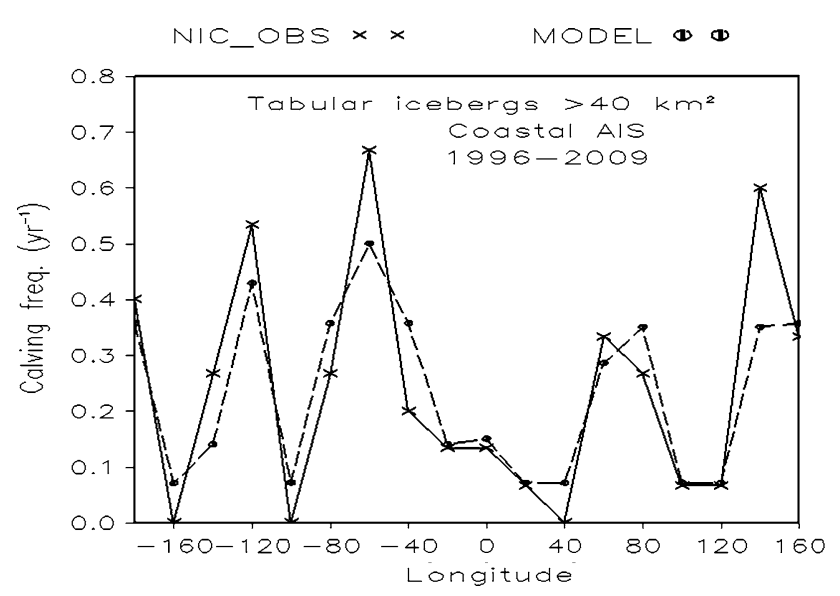

Fig. 8 Observed (crosses) and modelled (dots) calving rates along the Antarctica coast. The longitude bin is $20^{\circ}$. The observed iceberg location, size and timing (because icebergs are moving with ocean streams, time of observation must be put down) are available at http://www.natice.noaa.gov/products/south_icebergs_on_demand.html

seems to be supported by the fact that the bedrock topography in Eastern Antarctica is much smoother than under the WAIS (figure not shown). However, SEGMENT-Ice captures "first order" systematic calving, which produces the large, tabular icebergs.

\subsection{SEGMENT-Ice simulations in future climate scenarios (2000-2100)}

Given that the model has been shown to adequately reproduce the mass balance of the AIS over the past decade, confidence in the model projections of the future AIS mass balance is increased. The time series for the model simulations and GRACE observations of total mass changes are found to have high correlations of 0.84 . A scatterplot of the mass balance time series (obs vs. model simulation) has a regression slope of 1.2 , indicating that the mass loss is overestimated slightly in the model simulation. Given that the model and GRACE observations are independent, the model simulations appear to be good enough for future projections of the AIS mass loss.

The surface of Antarctica is quite smooth, except for the small outcrop regions and some coastal areas and can be delineated into twelve basins (A-K in Fig. 9). The net mass balances for 2010-2060 are projected for these basins and values are labelled in Fig. 9. It is a multi-model, multi scenario (e.g., for each climate model, the atmospheric forcing is based on three non-mitigated IPCC emission scenarios (SRESs): B1 (low rate of emission); A1B (medium); and A2 (high)) ensemble. Except the two ice shelves, Ross and Filchner-Ronne, which may gain 50 and $30 \mathrm{~km}^{3} / \mathrm{a}$ during the next 50 years, all other ten major basins have a mass loss. Usually the mass losses are concentrated at the lower reach of the basin where increasing flow divergence cannot be balanced by input from solid precipitation. For the next century, the vast inland areas have elevation changes $<0.1 \mathrm{~m}$. The geographic patterns of the areas with significant (above the levels expected from random variations in snowfall, assumed $>0.5 \mathrm{~m}$, see hatched areas in Fig. 9) elevation changes are like a band. The width of this band is about $200 \mathrm{~km}$ for West Antarctica and less than $50 \mathrm{~km}$ around the marginal areas of Indian Ocean sectors of East Antarctica. It is wide along the coast of Dronning Maud Land but smaller than West Antarctica
Fig. 9 The geographic distribution of total mass loss rates for 2010-2060. The surface elevations of Antarctica are flat, especially East Antarctica. Basin divisions therefore are obscure. Major drainage basins are labelled from $A$ to $K$, clockwise. Colored circle areas are proportional to the mass loss (red) and gain (blue) rates. For the next 50 years, mass loss rates are respectively $10,15,33,30,12$, $-50,55,37,90,92,-30$, and $47 \mathrm{~km}^{3} / \mathrm{a}$ for basins A-K. Areatotal mass loss rate is about $340 \mathrm{~km}^{3} / \mathrm{a}$. Hatched areas have significant elevation changes $(>0.5 \mathrm{~m})$ not attributable to random variations in solid precipitation

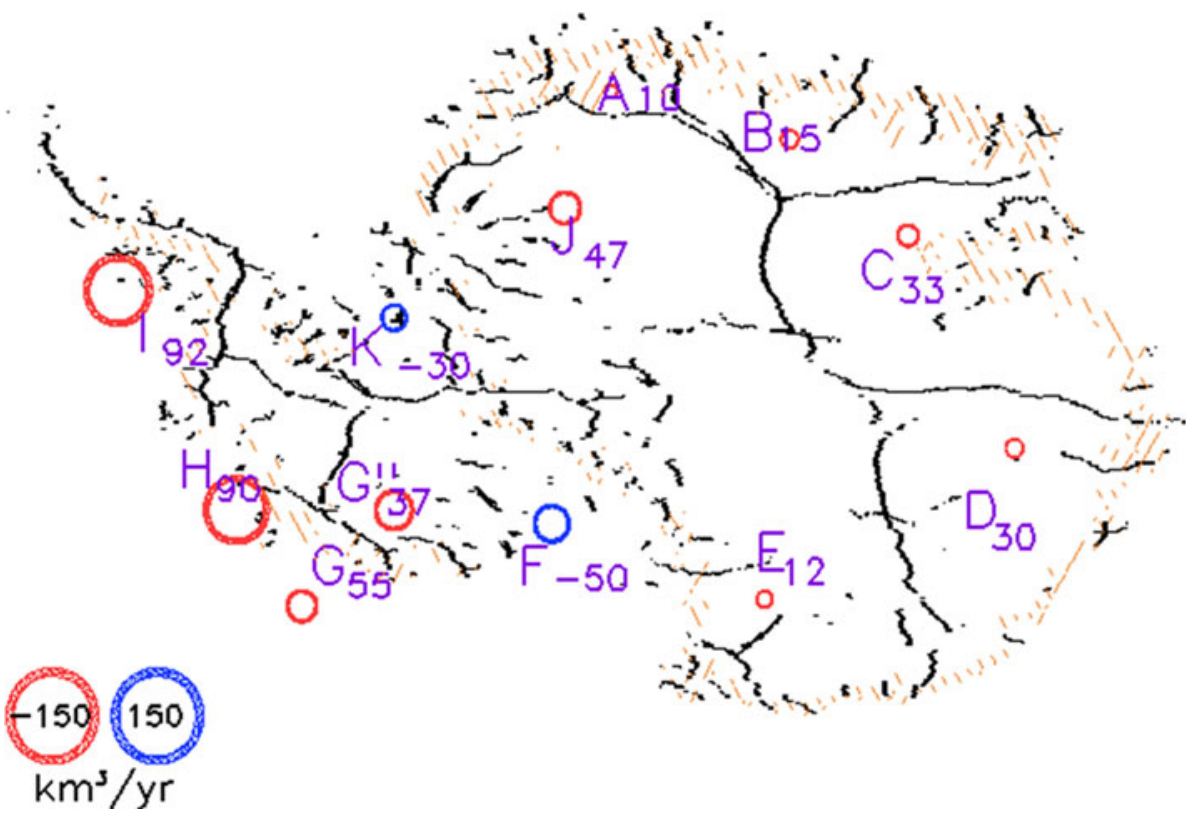



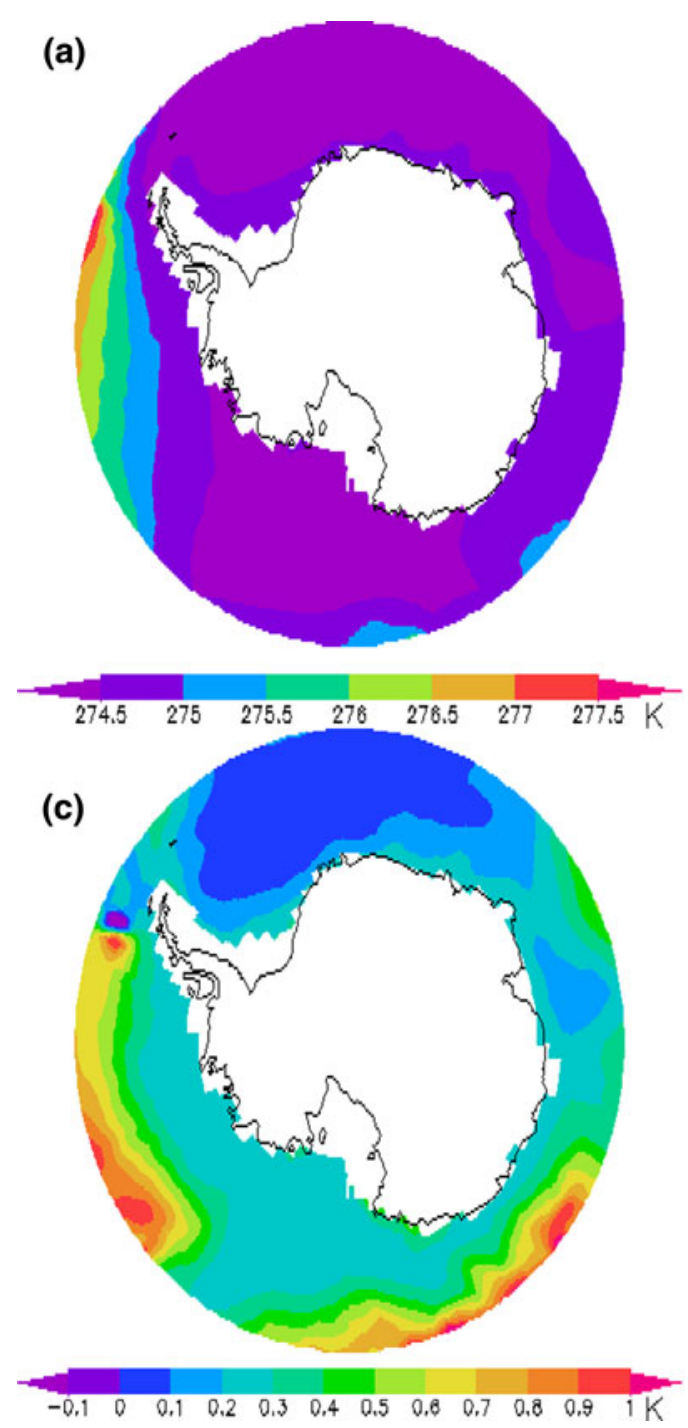

Fig. 10 Geographic distribution of (a) ocean temperature at 1,000 m, and (b) mean annual surface air temperature over Antarctica, from the CCSM3 A2 simulation. Changes in the same quantities over the twenty-first century are plotted respectively in panels (c) and (d). The annual mean temperature (d) increases by $\sim 7{ }^{\circ} \mathrm{C}$ over the

coasts. For the next 50 years, mass loss rates are respectively $10,15,33,30,12,-50,55,37,90,92,-30$, and $47 \mathrm{~km}^{3} / \mathrm{a}$ for basins A-K. The area total mass loss rate is $\sim 340 \mathrm{~km}^{3} / \mathrm{a}$. At Basins $\mathrm{A}$ and $\mathrm{B}$, flow divergence also significantly increases. However, with compensating increased snowfall, the net mass loss rate is small compared with other basins. The increased flow velocities at Thwaites and Pine Island Glaciers contribute most ( $>50 \%)$ to the mass loss at basin $\mathrm{H}$. The regional estimation for AP is uncertain because $5 \mathrm{~km}$ resolution cannot represent the details of ice geometry and ice flow. Also, atmospheric parameters from CGCMs, although downscaled, cannot represent the surface mass balance. (b)
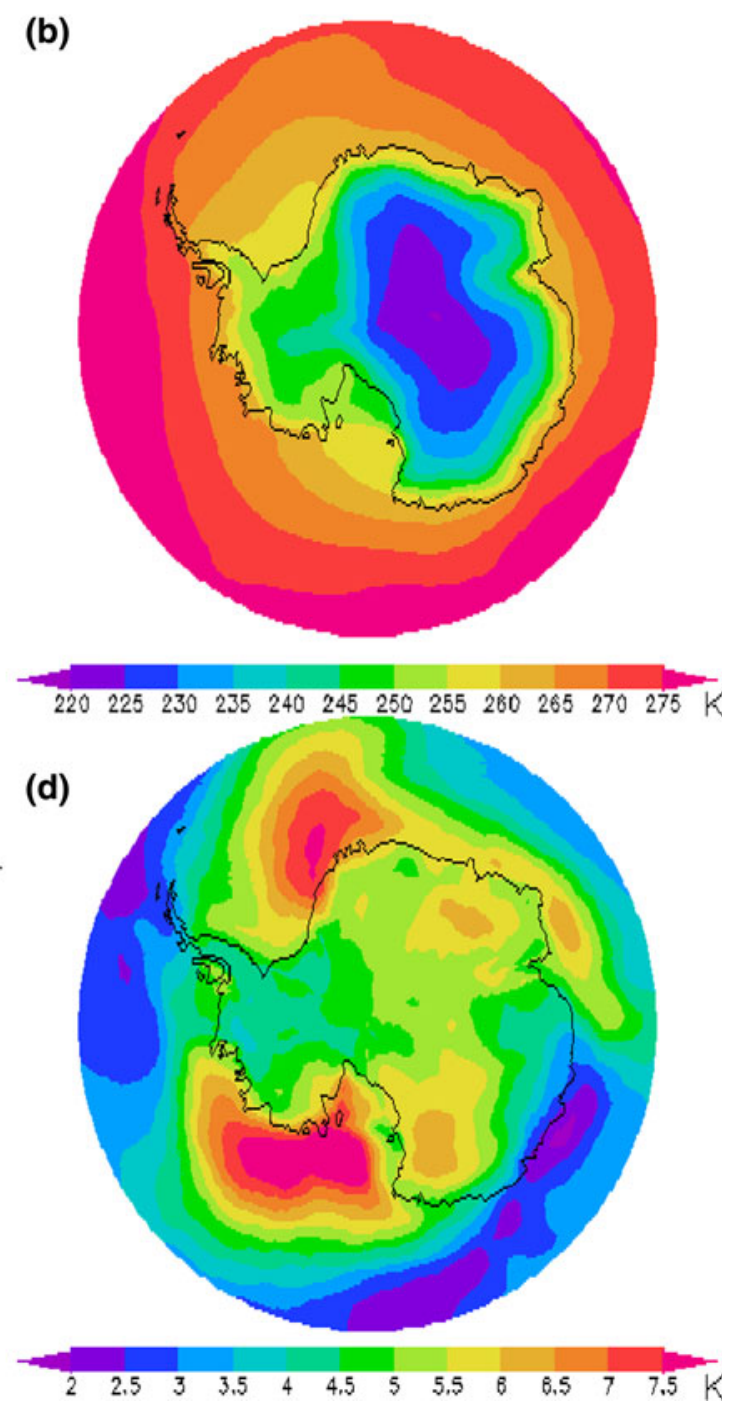

next century while the annual mean ocean temperature at $1,000 \mathrm{~m}$ increases by $<0.4{ }^{\circ} \mathrm{C}$. Due to the coarse resolution, AP cannot be seen clearly. However, West Antarctica facing the eastern Ross Sea warms faster than elsewhere in Antarctica

With the CCSM3 A2 scenario, SEGMENT-Ice simulates the calving rate of ice shelves and possible systematic cracks in inland ice for the twenty-first century. In general, large ice shelves (Filscher-Ronne and Ross Ice Shelves), and ice shelves at cold locations (Dronning Maud Land, Amery Ice Shelf) calve slowly; for example $\sim 10-25$ years on average over the Ross Ice Shelf. Shallower (thinner) ice shelves in relatively warmer environments calve faster but the icebergs are smaller. Different frontal sections of an ice shelf do not calve simultaneously (or, calving of an ice shelf is usually not achieved by one crack through the entire front in a direction perpendicular to spreading ice flow). At present, the western sector of the Ross Ice Shelf is 
very unstable. For the Amery Ice Shelf, its eastern sector is relatively unstable and is likely to have a systematic attrition before 2030. Compared with the Ross Ice Shelf, the calving frequency of the Filscher-Ronne Ice Shelf is sensitive to warming and will reduce to $\sim 13$ years on average (from $\sim 15$ years at present, according to Eq. (16). However, each systematic calving is smaller than for the Ross Ice Shelf, where typically there are two calving patterns to complete a systematic calving: one rift starts and increases at Roosevelt Island and extends westwards until it reaches the sea. The sector to the east, after losing neighboring support, calves within 2 years.

As the climate warms, increases of temperature and precipitation scale nonlinearly with GHG emission strength. Because increased temperature and precipitation are opposed contributors to ice mass balance, a numerical model is needed to ascertain the sign of the total mass change and to quantify inter-scenario differences. For the AIS, the widespread ice shelves make it sensitive to ocean temperature (Rignot et al. 2002; Bindschadler 2006). Using SEGMENT-Ice, it is possible to quantify the relative contributions from air temperature and ocean temperature increases. The heat flux from ocean to ice is in the form of sensible heat flux, as parameterized in Ren and Leslie (2011). Surface melting is a small part of mass loss and the effects of air temperature on surface mass balance are primarily through sublimation. For the present thickness profile of the ice shelves, the ocean temperature relevant to ice melt is the mid-level (800-100 m depth). Under the CCSM3 A2 scenario, of the total mass loss for the twenty-first century, ocean melt of the ice shelf accounts for less than $20 \%$. The main contribution to total mass loss is through increased ice discharge into surrounding oceans, especially the sector facing the Amundsen Sea. From Fig. 10, ocean temperatures only increase by $\sim 0.4^{\circ} \mathrm{K}$ during the twenty-first century, whereas air increases by $\sim 7^{\circ} \mathrm{K}$ at places over the WAIS, which is much larger. Furthermore, including salinity feedback and the slight difference in specific heat capacity, to match the $7^{\circ} \mathrm{K}$ air warming the ocean temperature must increase by $2^{\circ} \mathrm{K}$, which is not feasible. It is emphasized that ocean effects are persistent for both Antarctic ice shelves and marine terminating glaciers/ ice sheets, as $2 / 3$ of the WAIS is covered by marine-terminating ice. A changing ocean climate (e.g. Bindschadler 2006) could explain the synchronicity of the recent changes along the Amundsen coast, and has implications for projection stability of the WAIS in a changing ocean climate. The remaining question is how does ocean warming contribute to increased ice discharge.

\section{Conclusions}

Large uncertainty remains in the current and future mass balance and sea level contribution from the AIS. Climate warming increases snowfall in the interior but also enhances glacier discharge at the coast and ice melt at the interface of the ice shelves and the ocean. Recent studies documented the surface mass balance (van den Broeke et al. 2009; Lenaerts et al. 2012) and surface ice flow conditions (Rignot et al. 2011a, b). Here, a fully three dimensional ice dynamics/thermodynamics model, SEGMENT-Ice, is used that accounts for ice creeping in relation to basal sliding, thermal and mechanical structures of glacial ice.

The model-simulated ice velocities at ice surface level compare favourably with InSAR observations, for inland land ice, marine based ice and shelf ice. The model simulated total mass loss over Antarctica during 2003-2010 is verified against GRACE remote sensing data and satisfactory agreement is obtained. It is found that ice streams flowing into large ice shelves will thicken those ice shelves. Air temperature warming is the primary reason for significant mass losses in the Amundsen Sea and the northern Peninsula. Increased divergence associated with stream flow accounts for much of the mass loss. Snow precipitation in the twenty-first century is expected to increase but will not compensate for the mass loss from ice flow divergence. The non-local tabular calving scheme also is validated for estimating calving frequency. The exact timing and iceberg size still cannot be estimated accurately because the calving scheme captures only the first order calving mechanisms at present.

Recently observed fast flows (e.g., Rignot et al. 2008; $2011 \mathrm{a}, \mathrm{b})$ are explained by the ungrounding of glaciers owing to the thinning or collapse of their buttressing ice shelves or to a reduction in back force resistance at the ice front as glacier fronts thin because of warmer air or warmer ocean temperatures. This study finds that, in the upcoming century, air temperatures warm far more than ocean temperatures ( 5 vs. $0.2^{\circ} \mathrm{K}$ from a multiple model, multi-scenario mean of the WCRP CMIP3 archive for IPCC AR4). This warming causes a reduction in ice viscosity, which likely is the reason for the faster ice flow. A sensitivity experiment indicates that ocean temperature is critical for the fate of ice shelves. Gille (2002) showed that the 700-1000 meters ocean temperature has risen $0.17^{\circ} \mathrm{C}$ between 1950 and 1980. CGCMs project Southern Ocean temperature changes close to $0.4{ }^{\circ} \mathrm{C}$ between 1900 and 2100. One hypothesis, seemingly supported by recent mass balance surveys, is that in the Amundsen Sea and the western AP, ice shelf melting is enhanced by intrusions of warm circumpolar deep water onto the continental shelf and down into deep troughs carved into the sea floor during past ice ages (P. Molnar and J. Chen, personal communications, 2009). With $5-\mathrm{km}$ resolution data $(\sim 3 \mathrm{~km}$ in longitudinal direction at this latitude), the ice model cannot fully resolve the troughs. Future studies will use finer 
resolution digital elevation and ice thickness data. However, the ocean temperature increases in the upcoming century are limited. The model simulations raise another concern for the West Antarctica sector facing the Amundsen Sea; a possible increase of geothermal heat fluxes due to Earth mantle activities. SEGMENT-Ice simulations indicate that basal melting for this region is significantly larger than for the rest of Antarctica, possibly from active lava flow activity close to bedrock level. The flow directions that do not follow the ice and bedrock geometry likely are due to thermal regime influences of the geothermal heat fluxes.

Using CGCM projected precipitation and temperature to investigate likely changes in Antarctica ice volume has been carried out by Wild et al. (2003), in double $\mathrm{CO}_{2}$ experiments that indicated a warming over Antarctica and increased precipitation. Without considering ice flow, they suggest that the warming is insufficient to cause significant melting and that the dominant effect would be to compensate SLR from non-polar glaciers and ice caps, thermal expansion of the ocean and changes in terrestrial water storage. They are correct in that direct surface melt is not significant. However, according to our findings the ice viscosity will be reduced as the temperature increases and ice flow will be enhanced. The divergence of ice flow to feed ice to surrounding oceans is the primary loss mechanism for the AIS. In this modeling study, the AIS land ice has a net mass loss of $\sim 180 \mathrm{~km}^{3} / \mathrm{a}$ at present and this may double by year 2100 .

Acknowledgments We thank T. Hughes for his assistance in understanding ice shelf basics, and for key references he recommended. We also thank Professor D. MacAyeal for pointing us to many resources of which we were not aware. Useful discussions with Professors R. Thomas, J. Bamber, S. Jacobs, P. Bromirski, R. Bindschadler and $\mathrm{H}$. Conway greatly improved this manuscript. We also appreciate the contributions to this field by the late N. Reeh.

Open Access This article is distributed under the terms of the Creative Commons Attribution License which permits any use, distribution, and reproduction in any medium, provided the original author(s) and the source are credited.

\section{Appendix: Optimally retrieval of basal granular material properties}

Parameters of the granular layer control the resistance near the bedrock and are critical in deciding whether runaway instability (Ren et al. 2010) will occur. We here outline a dynamic data assimilation approach in optimally obtaining the granular material parameters in SEGMENT-Ice.

The granular mechanical properties and present thickness are inversely retrieved using SEGMENT-Ice, constrained by the goodness of fit between model simulated and observed surface ice velocities, over the entire AIS. The adjoint-based retrieval scheme is described in Ren (2004). Ice flow is sensitive to the granular basal parameters and the granular material thickness. Based on this sensitivity relationship, repeated runs of the SEGMENT-Ice model are performed with present ice geometry and ice temperature profiles, but with automatically varying granular layer thickness, to best fit the observed surface ice velocities. The metric for goodness of fit between the modelled and observed velocity fields is defined as

$$
\begin{aligned}
J & =\sum\left\|\overrightarrow{V_{\text {obs }}}-\overrightarrow{V_{\text {model }}}\right\| \\
& =\sum \sqrt{\left(u_{\text {obs }}-u_{\text {model }}\right)^{2}+\left(v_{\text {obs }}-v_{\text {model }}\right)^{2}}
\end{aligned}
$$

where $u, v$ are horizontal components of the full vector velocity. Subscripts 'obs' and 'model' are respectively the observed and modelled velocities. The observed ice velocities are obtained from the NASA/MEaSUREs project. In the cost function, the summation in the metric is only over regions with high quality observations.

The technique for obtaining the control variables (granular material properties) is an adjoint-based optimization scheme (Ren 2004). In short, each optimization iteration step requires the value of the cost function (Eq. 17) and its gradients with respect to control variables. The gradients are obtained from a backward integration of the adjoint system (an inverse modelling system strictly corresponding to SEGMENT-Ice).

Control variables need to have initial guess values. For Antarctica, the subglacial particle properties are initially specified according to studies using boreholes and seismic methods (Bentley 1991; Engelhardt et al. 1990). For example, under the WAIS, the rocks are mostly volcanic and the basalt clasts are of sizes of $\sim 5 \mathrm{~cm}$. Loose, ice cemented volcanic debris also are widespread around Mt. Erebus, Mt. Melbourne, and northern Antarctica Peninsula and its constituent blocks. The Transantarctic Mountains mostly have granitic basal rocks. In assigning granular particle sizes, geothermal pattern also are referenced because repeated phase changes at the interface of ice/rock arguably are the most efficient means of erosion and reduce the granular particle sizes. The particle size around Mt. Waesche ("W" in Fig. $3 ; 77^{\circ} \mathrm{S}$ and $130^{\circ} \mathrm{W}$ ) is assumed to be $<5 \mathrm{~cm}$ because of the local geothermal maxima.

\section{References}

Albrecht T, Martin M, Winkelmann R, Haselo M, Levermann A (2011) Parameterization for subgrid-scale motion of ice-shelf calving fronts. The Cryosphere 5:35-44 
Alley R, Meese D, Shuman C, Gow A (1993) Abrupt increase in Greenland snow accumulation at the end of the Younger Dryas event. Nature 362:527-529

Alley R, Dupont T, Parizek B, Anandakrishnan S, Lawson D, Larson G, Evenson E (2005) Outburst flooding and initiation of icestream surges in response to climatic cooling: a hypothesis. Geomorphology 75:76-89

Alley R, Horgan H, Joughin I, Cuffey K, Dupont T, Parizek B, Anandakrishnan S, Bassis J (2008) A simple law for ice-shelf calving. Science 322:1344

Amezcua J, Kalnay E, Williams P (2011) The effects of the RAW filter on the climatology and forecast skill of the SPEEDY model. Mon Weath Rev 139:608-619. doi:10.1175/2010MWR3530.1

Anderson S (2006) Impact of mineral surface area on solute fluxes at Bench Glacier, Alaska. In: Peter G (ed) KnightGlacier science and environmental change. Blackwell Science Ltd, Malden, pp 79-81

Bamber J, Ekholm S, Krabill W (2001) A New, high-resolution digital elevation model of Greenland fully validated with airborne laser altimeter data. J Geophys Res 106:6733-6745

Bamber J, Gomez-Dans J, Griggs J (2009) A new $1 \mathrm{~km}$ digital elevation model of the Antarctic derived from combined satellite radar and laser data-part 1: data and methods. The Cryosphere 3:101-111

Bentley C (1991) Configuration and structure of the subglacial crust. In: Tinguey RJ (ed) The geology of Antarctica. Oxford University Press, Oxford, pp 335-364

Bentley C (1993) Antarctic mass balance and sea level change. Eos 74(50):585-586

Bentley C, Giovinetto M (1990) Mass balance of Antarctica and sea level change. In: Proceedings of the international conference on the role of the polar regions in global change, pp 481-488

Bentley C, Giovinetto M (1991) Mass balance of Antarctica and sea level change. In: Weller G, Wilson CL, Sevberin BAB (eds) International conference on the role of the polar regions in global change: proceedings of a conference, vol II. University of Alaska, Fairbanks, Geophysical Institute/Centre for Global Change and Arctic Systems Research, Fairbanks, pp 481-488

Berger A, Loutre M (2002) An exceptionally long interglacial ahead? Science 297:1287-1288

Bindschadler R (2006) Hitting the ice sheet where it hurts. Science 311:1720-1721

Bromirski P, Sergienko O, MacAyeal D (2010) Transoceanic infragravity waves impacting Antarctic ice shelves. Geophys Res Lett 37:L02502

Crosson W, Laymon C, Inguva R, Schamschula M (2002) Assimilating remote sensing data in a surface flux-soil moisture model. Hydrol Proc 16:1645-1662

Davis C et al (2005) Snowfall-driven growth in East Antarctic ice sheet mitigates recent sea-level rise. Science 308:1898-1901

De Angelis H, Skvarca P (2003) Glacier surge after ice shelf collapse. Science 299:1560-1562

Engelhardt $\mathrm{H}$ et al (1990) Physical conditions at the base of a fast moving Antarctica ice stream. Science 248:57-59

Gille J (2002) Warming of the southern ocean since the 1950s. Science 295:1275-1277

Glasser N, Scambos T (2008) A structural glaciological analysis of the 2002 Larsen B ice shelf collapse. J Glaciology 54:3-16

Greve R (2005) Relation of measured basal temperatures and the spatial distribution of the geothermal heat flux for the Greenland ice sheet. Ann Glaciol 42:424-432

Hooke R (1981) Flow law for polycrystalline ice in glaciers: comparison of theoretical predictions, laboratory data, and field measurements. Rev Geophys Space Phys 19:664-672
Hughes T (1992) Theoretical calving rates from glaciers along ice walls grounded in water of variance depths. J Glaciology 38:282-294

Hughes T (2002) Calving bays. Quat Sci Rev 21:267-282

Hughes T (2011) A simple holistic hypothesis for the self-destruction of ice sheets. Quat Sci Rev 20:1829-1845

Huybrechts P, Gregory J, Janssens I, Wild M (2004) Modelling Antarctic and Greenland volume changes during the 20th and 21 st centuries forced by GCM time slice integrations. Glob Plan Change 42:83-105

IPCC AR4 (2007) Climate change 2007: the physical science basis. In: Solomon S, Qin D, Manning M (eds) Contribution of working group I to the fourth assessment report of the intergovernmental panel on climate change

Ivins E, James T (2005) Antarctic glacial isostatic adjustment: a new assessment. Antarct Sci. 17:541-553

Jacobs S, Hellmer H, Doake C, Jenkins A, Frolich R (1992) Melting of ice shelves and the mass balance of Antarctica. J Glaciol $38: 375$

Jaeger J (1969) Elasticity, fracture and flow. Methune \& CO. Ltd, New Fetter Lane

Jezek K (2008) The RADARSAT-1 Antarctic mapping project. BPRC report no. 22, Byrd Polar Research Center, The Ohio State University, Columbus, Ohio, p 64

Joughin I, MacAyeal D (2005) Calving of large tabular icebergs from ice shelf rift systems. Geophys Res Lett 32:L02501

Joughin I, Tulaczyk S (2002) Positive mass balance of the Ross Ice Streams, West Antarctica. Science 295:476-480

Kalnay E et al (1996) The NCEP/NCAR 40-year reanalysis project. Bull Amer Meteor Soc 77:437-471

Kenneally J, Hughes T (2006) Calving giant icebergs: old principles, new applications. Antarct Sci 18:409-419

Lenaerts J, van den Broeke M, van de Berg W, van Meijgaard E, Kuipers Munneke P (2012) A new, high-resolution surface mass balance map of Antarctica (1979-2010) based on regional atmospheric climate modelling. Geophys Res Lett 39:L04501

Liston G, Bruland O, Winther J-G, Elvehoy H, Sand K (1999) Meltwater production in Antarctic blue-ice areas: sensitivity to changes in atmospheric forcing. Polar Res 18:283-290

MacAyeal D (1989) Large-scale ice flow over a viscous basal sediment: theory and application to ice stream B, Antarctica. J Geophys Res 94:4071-4087

MacAyeal D (1992) Irregular oscillations of the west Antarctic ice sheet. Nature 359:29-32

Martin M, Winkelmann R, Haseloff M, Albrecht T, Bueler E, Khroulev C, Levermann A (2011) The potsdam parallel ice sheet model (PISM-PIK) - Part 2: dynamic equilibrium simulation of the Antarctic ice sheet. The Cryosphere 5:727-740

Massom R, Hill K, Barbraud C, Adams N, Ancel A, Emmerson L, Pook M (2009) Fast ice distribution in Adelie Land, East Antarctica: interannual variability and implications for emperor penguins Aptenodytes forsteri. Mar Ecol Prog Ser 374:243-257

Pralong A, Funk M (2005) Dynamic damage model of crevasse opening and application to glacier calving. J Geophysical Res (Solid Earth) 110:B01309

Reeh N (1968) On the calving of ice from floating glaciers and ice shelves. J Glaciol 7:215-232

Ren D (2004) 4DVAR retrieval of prognostic land surface model variables for ARPS". University of Oklahoma, Norman $236 \mathrm{pp}$

Ren D, Leslie L (2011) Three positive feedback mechanisms for ice sheet melting in a warming climate. J Glaciol 57:206-211

Ren D, Fu R, Leslie L, Karoly D, Chen J, Wilson C (2010) A new ice sheet model validated by remote senseing of the Greenland ice sheet. Central Eur J Geosci. doi:10.2478/v10085-010-0012-9 
Ren D, Fu R, Leslie L, Karoly D, Chen J, Wilson C (2011a) A multirheology ice model: formulation and application to the Greenland ice sheet. J Geophys Res 116:D05112

Ren D, Fu R, Leslie L, Karoly D, Chen J, Wilson C (2011b) The Greenland ice sheet response to transient climate change. J Clim 24:3469-3483

Rignot E, Jacobs S (2002) Rapid bottom melting widespread near Antarctic ice sheet grounding lines. Science 296:2020-2023

Rignot E, Thomas R (2002) Mass balance of polar ice sheets. Science 297:1502-1506

Rignot E, Vaughan D, Schmeltz M, Dupont T (2002) Acceleration of Pine Island and Thwaites Glaciers, West Antarctica. Ann Glaciol 34:189-194

Rignot E, Casassa G, Gogineni P, Krabill W, Rivera A, Thomas R (2004) Accelerated ice discharge from the Antarctic Peninsula following the collapse of Larsen B ice shelf. Geophys Res Lett. doi:10.1029/2004GL020697

Rignot E et al (2005) Recent ice loss from the Fleming and other glaciers, Wordie Bay, West Antarctic Peninsula. Geophys Res Lett $32: 1-4$

Rignot E, Bamber J, van den Broeke M, Davis C, Li Y, van de Berg W, van Meijgaard E (2008) Recent mass loss of the Antarctic Ice Sheet from dynamic thinning. Nature Geosci. doi:10.1038/ngeo 102

Rignot E, Mouginot J, Scheuchl B (2011a) Ice flow of the Antarctic ice sheet. Science 333:1427-1430

Rignot E, Velicogna I, van den Broeke M, Monaghan A, Lenaerts J (2011b) Acceleration of the contribution of the Greenland and Antarctic ice sheets to sea level rise. Geophys Res Lett 38: L05503

Rist M, Sammonds P, Murrell S, Meredith P, Doake C, Oerter H, Matsuki K (1999) Experimental and theoretical fracture mechanics applied to Antarctic ice fracture and surface crevassing. J Geophys Res 104:2973-2987

Scambos T, Hulbe C, Fahnestock M (2003) Climate-induced ice shelf disintegration in the Antarctic Peninsula. In Antarctic Peninsula climate variability: historical and paleoenvironmental perspectives. Antarct Res Ser 79:79-92

Scambos T, Bohlander J, Shuman J, Skvarca P (2004) Glacier acceleration and thinning after ice shelf collapse in the Larsen B embayment, Antarctica. Geophys Res Lett 31:L18402

Scambos T, Sergienko O, Sargent A, MacAyeal D, Fastook J (2005) ICESat profiles of tabular iceberg margins and iceberg break-up at low latitudes. Geophys Res Lett. doi: 10.1029/2005GL023802

Shapiro N, Ritzwoller M (2004) Inferring surface heat flux distributions guided by a global seismic model: particular application to Antarctica. Earth Planet Sci Lett 223:213-224

Shepherd A, Wingham D (2007) Recent sea-level contributions of the Antarctic and Greenland ice sheets. Science 315:1529-1532

Shepherd A, Wingham D, Payne T, Skvarca P (2003) Larsen ice shelf has progressively thinned. Science 302:856-859

Stammerjohn S, Martinson D, Smith R, Iannuzzi R (2008) Sea ice in the western Antarctic Peninsula region: Spatio-temporal variability from ecological and climate change perspectives. Deep Sea Res Part II Top Stud Oceanogr. doi:10.1016/j.dsr2.2008. 04.026

Tapley B, Bettadpur S, Ries J, Thompson P, Watkins M (2004) GRACE measurements of mass variability in the Earth system. Science 305:503-505
Thomas R (1973) The creep of ice shelves: theory. J Glaciol 12:45-53 Thomas R et al (2004) Accelerated sea level rise from West Antarctica. Science 306:255-258

Thomas R, Frederick E, Krabill W, Manizade S, Martin C (2006) Progressive increase in ice loss from Greenland. Geophys Res Lett 33:L10503

van den Broeke M, van de Berg W, Van Meijgaard E (2006) Snowfall in West Antarctica much greater than previously assumed. Geophys Res Lett 33:L02505. doi: 10.1029/2005GL025239

van den Broeke M, Bamber J, Ettema J, Rignot E, Schrama E, van de Berg W, van Meijgaard E, Velicogna I, Wouters B (2009) Partitioning recent Greenland mass loss. Science 326:984-986

van der Veen C (1999) Fundamentals of glacier dynamics. A.A. Balkema, Rotterdam, Netherlands, p 472

van der Veen C, Whillans I (1989) Force budget: I. Theory and numerical methods. J Glaciol 35:53-60

Vaughan D (1993) Relating the occurrence of crevasses to surface strain rates. J Glaciol 39:255-266

Vaughan D (2006) Recent trends in melting conditions on the Antarctic Peninsula and their implications for ice-sheet mass balance and sea level. Arct Antarct Alp Res 38:147-152

Velicogna I, Wahr J (2006) Measurements of time-variable gravity show mass loss in Antarctica. Science 311:1754-1756. doi: 10.1126/science. 1123785

Vieli A, Payne A, Du Z, Shepherd A (2007) Causes of precollapse changes of the Larsen B ice shelf: numerical modelling and assimilation of satellite observations. Earth Planet Sci Lett 259:297-306

Wang W, Warner R (1999) Modelling of anisotropic ice flow in Law Dome, East Antarctica. Ann Glaciol 29:184-190

Watanabe O (1997) Antarctica: east queen Maud Land-Enderby Land Glaciological Folio. National Institute of Polar Research, Japan

Wen J, Jezek K, Monaghan A, Sun B, Ren J, Huybrechts P (2006) Accumulation variability and mass budgets of the Lambert Glacier-Amery Ice shelf system at high elevations. Ann Glaciol 43:351-360

Wild M, Calanca P, Scherrer S, Ohmura A (2003) Effects of polar ice sheets on global sea level in high-resolution greenhouse scenarios. J Geophys Res. doi: 10.1029/2002JD002451

Williams P (2009) A proposed modification to the Robert-Asselin time filter. Mon Weather Rev 137:2538-2546

Wingham D, Ridout A, Scharroo R, Arthern R, Shum C (1998) Antarctic elevation change from 1992 to 1996 . Science 282:456458

Winkelmann R, Martin M, Haseloff M, Albrecht T, Bueler E, Khroulev C, Levermann A (2011) The potsdam parallel ice sheet model (PISM-PIK) - part 1: model description. The Cryosphere 5:715-726

Yu J, Liu H, Jezek K, Warner R, Wen J (2010) Analysis of velocity field, mass balance, and basal melt of the Lambert GlacierAmery Ice Shelf system by incorporating Radarsat SAR interferometry and ICESat laser altimetry measurements. J Geophys Res 115:B11102. doi:10.1029/2010JB007456

Zwally H, Giovinetto M, Li J, Cornejo H, Beckley M, Brenner A, Saba J, Yi D (2005) Mass changes of the Greenland and Antarctic ice sheets and shelves and contribution to sea level rise: 1992-2002. J Glaciol 51:509-527 